\title{
The Mid-Life Dip in Well-Being: a Critique
}

\author{
David G. Blanchflower ${ }^{1,2,3}$ (D) . Carol L. Graham ${ }^{4,5,6}$
}

Accepted: 3 August 2021 / Published online: 19 October 2021

(c) The Author(s), under exclusive licence to Springer Nature B.V. 2021

\begin{abstract}
A number of studies-including our own-find a mid-life dip in well-being. Yet several papers in the psychology literature claim that the evidence of a U-shape is "overblown" and if there is such a thing that any such decline is "trivial". Others have claimed that the evidence of a U-shape "is not as robust and generalizable as is often assumed," or simply "wrong." We identify 409 studies, mostly published in peer reviewed journals that find U-shapes that these researchers apparently were unaware of. We use data for Europe from the Eurobarometer Surveys (EB), 1980-2019; the Gallup World Poll (GWP), 2005-2019 and the UK's Annual Population Survey, 2016-2019 and the Census Bureau's Household Pulse Survey of August 2021, to examine U-shapes in age in well-being. We find remarkably strong and consistent evidence across countries of statistically significant and nontrivial U-shapes in age with and without socio-economic controls. We show that studies cited by psychologists claiming there are no U-shapes are in error; we reexamine their data and find differently. The effects of the mid-life dip we find are comparable to major life events such as losing a spouse or becoming unemployed. This decline is comparable to half of the unprecedented fall in well-being observed in the UK in 2020 and 2021, during the Covid19 pandemic and lockdown, which is hardly "inconsequential" as claimed.
\end{abstract}

Keywords Well-being $\cdot$ Age $\cdot$ Happiness

"There is abundant empirical evidence pointing towards a 'U-curve' of happiness across the lifespan (Blanchflower \& Oswald, 2008). When various measures of lifetime happiness are represented on a graph, with time as the $\mathrm{x}$ axis and degree of happiness as the $\mathrm{y}$ axis, a U-shape appears. Early life and, contra intuition, old age are the happiest periods, with

David G. Blanchflower

blanchflower@dartmouth.edu

1 Bruce V. Rauner Professor of Economics, Department of Economics, Dartmouth College, Hanover, USA

2 Adam Smith Business School, University of Glasgow, Glasgow, Scotland

3 GLO, Bloomberg and NBER, Newyork, USA

4 Leo Pasvolsky Senior Fellow The Brookings Institution, Washington, DC, USA

5 College Park Professor, University of Maryland, College Park, MD, USA

6 Senior Scientist, Gallup, Washington, DC, USA 
midlife forming the base of the curve as the part in which one is most prone to unhappiness and depression. This has been replicated in a variety of contexts with extremely large datasets (Blanchflower \& Oswald, 2009)."

Christopher Wareham, C.S. (2021). Between hoping to die and longing to live longer. History and Philosophy of the Life Sciences, 43, 40.

\section{Introduction}

Several economic studies, including our own ${ }^{1}$ have recently found evidence of a significant and empirically large downturn in human well-being during the mid-life years - socalled 'happiness curves' (Rauch, 2018). The U-shape in well-being has now been found in 145 countries (Blanchflower, 2020a). The research now extends to trends in unhappiness, stress, lack of sleep, depression, and even suicide (Daly et al, 2011) and across large numbers of data sets, multiple measures of unhappiness and countries as well as over time (Blanchflower, 2020b). Every US state has a U-shape (Blanchflower \& Graham, 2020). There is within-person evidence of a U-shape from longitudinal surveys which focuses on changes in life satisfaction as a linear function of individual age (Cheng, Powdthavee and Oswald, 2017). Controlling for cohort effects has little or no impact on the U-shape (Clark, 2019 and Blanchflower, 2020b). There is a hill-shape in anti-depressant use which maximizes in the mid-40 s in European countries (Blanchflower \& Oswald, 2016), and in stress across a large number of countries in the Gallup World Poll (Graham and Ruiz-Pozuelo). The U-shape pattern in mid-life even extends beyond humans to apes (Weiss et al., 2012).

There are many explanations for the U-shape, some of them even biological, as the paper on the U-curve in apes suggests. Some of them, though, seem to be a natural part of the aging process. Individuals learn to adapt to their strengths and weaknesses over time, and become much more realistic in their expectations, as they age. They also become emotionally 'wiser' and have fewer emotional swings (Rauch, 2018), and appreciate life more as they age, not least as they are much more likely to see friends and siblings die. The young have less experience navigating stressful experiences than do older people. Mid-life, meanwhile, tends to bring an increase in stressful experiences, such as having dependent children and dependent parents at the same time. And, finally, a small part of the explanation, as we note below for the over 70's, is that happier people are healthier and tend to live longer, creating a selection effect in the older tail of the age distribution.

Most recently, the increases in the U.S. deaths of despair due to drugs, alcohol, and suicide occur precisely in the middle-aged, 35-64 years (Case \& Deaton, 2015, 2020). The trends in these deaths have a robust association with the same ill-being markers-unhappiness and stress - that increase in mid-life and are responsible for driving up the overall mortality rate (Graham and Pinto, 2019). A recent analysis by the OECD in How's Life, 2020 shows that deaths of despair, by suicide, alcohol abuse or drug overdoses are higher

\footnotetext{
1 We have published papers on the U-shape in well-being for over a period of nearly two decades including Blanchflower (2020a, 2020b, 2020c); Blanchflower and Oswald (2019; 2016; 2009; 2008; 2004a and 2004b; Graham, C., (2017, 2010); Graham, Eggers and Sukhtankar (2004); Graham, Laffan and Pinto (2018); Graham and Pettinato (2002) and Graham and Ruiz-Pozuelo (2017) and Blanchflower and Graham (2021a, 2021b, 2020).
} 
in ten OECD countries-Slovenia; Lithuania; Latvia; Korea; Denmark; Belgium; Hungary; Austria; Finland and Poland - than they are in the United States. ${ }^{2}$

Blanchflower and Oswald (2020) show that despair, measured as every one of the prior thirty days being a bad mental health day has doubled over the last two decades. By 2019 one in eight prime-age white low educated workers were in despair on this measure. Blanchflower and Feir (2021), using the same data, find that despair is especially high also among Native Americans. Graham and Pinto (2021) found those out of the labor force in this same cohort have the worst reported well-being and objective health of any other labor group, with high levels of despair, reported pain, and disease diagnostics. They are also more likely to live in their parents' homes or census tracts-contributing to the decline in U.S. geographic mobility, a critical means to finding new jobs.

There is some debate about the existence of the U-shape. In what follows we examine that evidence. We start off by surveying the literature. We critique some earlier studies in psychology that were based on small samples. We also re-examine claims from earlier papers and re-estimate equations and find different conclusions. We then discuss evidence provided in three recent papers from psychologists arguing the claims of the existence of U-shapes are 'wrong' (Galambos et al, 2021a) or trivial (Jebb et al, 2020). We examine their claims and show a) they were based on wrongly classifying research findings b) they surveyed a highly selective list of 28 papers, 21 of which found U-shapes, but ignored 388 additional papers including a further 353 in peer-reviewed journals in English finding the opposite of what they claim ${ }^{3}$. In a response (Galambos et al., 2021a, 2021b) maintained the same conclusion and did not even discuss any of the new evidence.

It is important to be clear about what dimensions of well-being we are referring to and using in our data. For the most part, we focus on life satisfaction and happiness, which are both life course evaluations of positive well-being, usually assessed on 4, 5, 7, or 11-point scales. Life satisfaction is generally the preferred measure, as it is more clearly framed, compared to happiness, which can be confused with momentary contentment. Yet it was the most widely used question in many of the earlier surveys, in which respondents were asked how happy they are with their lives as a whole. ${ }^{4}$ The two terms are used interchangeably in much of the literature and in this paper where they reflect the question that is asked in the particular data we are referring to. In practice, responses to the two questions correlate very closely, as do the variables that are associated with the patterns in them. In

\begin{tabular}{lcccc}
\hline \multicolumn{5}{c}{ Rates from their Fig. 5.5 are as follows per 100,000 population, $2016(\%)}$. \\
Suicide & Acute alcohol abuse & Drug overdose & All \\
SVN & 18.1 & 10.7 & 0.2 & 29.0 \\
LTU & 26.7 & 0.8 & 0.1 & 27.6 \\
LVA & 18.1 & 8 & 0.2 & 26.3 \\
KOR & 24.6 & 1.5 & 0 & 26.1 \\
DNK & 9.4 & 10.5 & 0.5 & 20.4 \\
BEL & 15.9 & 3 & 0.5 & 19.4 \\
HUN & 16.2 & 3.2 & 0 & 19.4 \\
AUT & 12.2 & 4.8 & 1.1 & 18.1 \\
FIN & 13.9 & 3.3 & 0.9 & 18.1 \\
POL & 11.6 & 6.2 & 0 & 17.8 \\
USA & 13.9 & 2.8 & 0.9 & 17.6 \\
${ }^{3}$ GKJL1 reported 20 cross-section estimates and 13 longitudinal but of these five papers produced both \\
cross-section and longitudinal results, hence there are 28 papers examined. \\
${ }^{4}$ For example, the Eurobarometer survey series taken across European countries for decades, that we use \\
below, asks a 4-step life satisfaction question.
\end{tabular}


some cases, we also use markers of ill-being, such as stress, despair, and reported depression. As discussed below, the age relationship with these markers displays a hump rather than $\mathrm{U}$ shape, peaking again in the mid-life years.

We also present nationally representative data from the UK's national statistical office, the ONS, showing that the fall in well-being from youth to midlife is far from trivial. Indeed, the fall is approximately half the size of the record breaking drops in well-being observed in the COVID pandemic. It is also comparable to the size of well-being declines such as losing a spouse or becoming unemployed. Finally, we present supporting evidence from the US Census Bureau showing that the taking of prescription medications traces out an inverse U-shape. We conclude with a discussion of the evidence.

\subsection{Older Studies}

A few prominent papers in the past in psychology and economics dismiss the mid-life downturn as an illusion. An earlier review by Ulloa et al. (2013) goes as far as to draw the conclusion that "extant studies ... show either a U-shaped, inverted U-shaped or linear relation between ageing and subjective well-being." Myers (2000, p. 58) argued that "Although many people believe there are unhappy times of life-times of adolescent stress, midlife crisis, or old age decline-repeated surveys across the industrialized world reveal that no time in life is notably happiest and most satisfying". In contrast, Michael Argyle, concluded that studies of life satisfaction found happiness increased with age (Argyle, 1999, 2001). Palmore and Luikhart (1972) argue that age has little or no relationship with life satisfaction.

Many of the earlier studies cited in the psychology literature were based on very small samples such as Prenda and Lachman (2001) $(n=2974)$, Charles et al. $(n=2804)$; Mroczek and Kolarz $(n=2727)$; Mroczek and Spiro $(n=1927)$, Hamarat et al. (with 95 observations); Carstensen et al (2011) $(n=184$ in one sample and $n=194$ in another). Helson and Lohnen (1998) $(\mathrm{n}=80)$ and Gross et al. (1997) with four studies (study 1; $\mathrm{n}=127$; study $2 ; n=49 ;$ study $3 ; n=82$ and study $4 ; n=1080)$ and Freund and Baltes $(1998)(n=206)$. Palmore and Luikhart (1972) $(n=502$ for ages 45-69). It is hard to say much of anything about statistical differences in well-being by age with sample sizes this small. Assuming the samples looked at are from age 20 to 70 with a sample size of 200 that averages about four people per age cell. While this may be usual for clinical studies, samples this size tend not to yield robust econometric analysis.

Easterlin claims "happiness is greatest at midlife but not by a great deal. On average it rises somewhat as people progress from age 18 to 51 and declines thereafter" (2006, p. 471). A survey by Diener et al., (1999, p. 291) concluded that "although a small decline in life satisfaction in age is often found the relation is eliminated when other variables such as income are controlled. More important to note is that other recent studies converge to show that life satisfaction often increases, or at least does not drop, with age." Diener and Su (1998) examined World Values Survey data for 1994 and argued that the raw data on life satisfaction "trended up slightly through age." Deaton (2008) concluded that the U-shaped relation is present solely in rich, English- speaking countries in which the elderly is relatively satisfied with their lives. In his words, "for most of the world, life satisfaction declines with age; the exceptions being among the very highest-income countries-including the United States, Canada, United Kingdom, Australia, and New Zealand-where life satisfaction is U-shaped with age, falling at first and rising after middle age" (ibid., p. 8). 
Even when U-shapes were found they were frequently dismissed as largely irrelevant, and the scale of the effects were frequently classified as trivial. For example, Cantril (1965) is often cited as finding no evidence of a U-shape in well-being although his study in fact shows them. When asked to indicate their thoughts about their current life $24.2 \%$ of those age $<29 ; 22.3 \%$ of those 30-49 and $29.3 \%$ of those 50+ responded in the high range! On the other hand, 27.5\%, $29.1 \%$ and $25.2 \%$ responded in the low range of the ladder scale ${ }^{5}$. These look like U-shapes.

Diener et al (1999) citing Inglehart (1990) went on to argue that "international studies based on representative samples from multiple countries also show that life satisfaction does not decline with age." Myers (1992), for example, had also argued that Inglehart showed that "age differences in well-being were trivial. Does happiness then align itself more with any particular age? Do young adults have more fun? Surprisingly, and definitely, not" (p.69).

Ingelhart (1990) examined well-being across sixteen nations using data from the Eurobarometer (\#13-\#26 covering the period April 1980- November 1986) and the World Values Survey for the United States, Canada, Hungary and Japan for 1981-1982 and argued that there was "little variation by age" in well-being (p.224). He did, however, note that "we do find a slight curvilinear tendency with both indicators, such that satisfaction and happiness decline slightly from the youngest to the middle-aged groups and then rise again among the oldest group."

It turns out that in the raw data Inglehart reported on page 225, there were obvious U-shapes in age for nine of the sixteen countries as well as overall in happiness ${ }^{6}$. Using happiness from Eurobarometer \#18 and \#19 and modelling who said very happy-controlling for income, occupation, education, nationality and marital status-he found the following pattern by age: $15-24=21 \% ; 25-34=21 \% ; 35-44=19 \% ; 45-54=21 \%$ and $65+=29 \%$. More on this below, where we use the same data and conclude there are indeed substantive U-shapes in age, contrary to the claims of what appears to be a generation of psychologists.

Given the reach of this phenomenon across a large proportion of the world's population, and its association with other behaviors that are indicative of poor psychological and physical health, we believe it is important to resolve this debate. The significant evidence that we present in this paper from our most recent work in addition to that of earlier studies, makes it difficult to refute the claim that the mid-life dip is significant, both statistically and in terms of human experience.

\subsection{Recent Controversies}

In a recent critique Galambos et al. (2020)—henceforth GKJL1-surveyed 28 papers selected using the following criteria.

a) Published from January 2013 to June 2019 .

b) Published in a peer reviewed journal in English.

c) Tested for age differences (cross-sectional) or changes with age (longitudinal) in global measures of life satisfaction or happiness.

\footnotetext{
5 As reported in Diener and Suh (1998), p. 307.

6 From Table 7.4 there are U-shapes in age for the following with \%very happy at 15-24 and 45-54 and $65+$ in parentheses overall $(24,21,23)$; Netherlands $(47,38,45)$; Denmark $(39,32 *, 34)$; Canada $(39,26$, $36)$; Ireland (32, 29, 39); Belgium (29, 23, 26); Spain (25, 19, 22); France (19, 10, 14); Italy (12, 8, 10) Greece $(12,10,13) *=$ age $55-64$.
} 
d) Spanned the teens or $20 \mathrm{~s}$ into the $60 \mathrm{~s}$ (cross-sectional studies) or had at least two times of measurement and spanned the periods of young adulthood to midlife, midlife to late life, or young adulthood to midlife to late life (longitudinal studies).

Having analyzed these 28 papers, that generated 33 different findings, twenty crosssection, thirteen longitudinal: five of the papers had both cross-section and longitudinal estimates, they reported that for the cross-section studies, seven found U-shapes; three did not and 10 were mixed. For the thirteen longitudinal studies they reported that five studies found U-shapes while four did not with a further four 'mixed'. On the basis of this, what we will show from a flawed summary, the authors concluded that "the purported $U$ shape is not as generalizable or robust as often portrayed,"

They later note on the 'purported' U-shape:

"The purported $U$ shape in happiness is interpreted by a number of economists as evidence that, as people move through the life course, they will experience a midlife trough, sometimes labeled a midlife crisis."

That is exactly what the evidence presented in this current paper supports.

GKJL1 went even further and claimed the following.

"We believe the conclusion that happiness declines from late adolescence to midlife (the first half of the U-shape) is premature, and possibly wrong." They also claim that "given the body of evidence over recent years, we cannot conclude that there is a universal U shape in happiness."

We disagree. In what follows we argue that given the body of evidence over recent years, it is clearly possible to conclude that there is a universal U shape in happiness. The evidence we present supports the conclusion that there is a decline in well-being from youth to midlife, rather than 'premature' and 'wrong'. We provide a detailed rebuttal of these claims, several of which are unusual to say the least.

Blanchflower and Graham (2021a, 2021b)—henceforth B\&G-challenged the conclusion that the finding of a U-shape was wrong by noting that most of the estimates the authors evaluated were misclassified and once those errors were corrected almost all found U-shapes and none didn't. In regard to the twenty studies using cross-section data, B\&G showed one paper had to be excluded as it didn't fit GKJL's own criteria; three were 'mixed' and sixteen of the papers found U-shapes. In regard to the thirteen studies that used longitudinal data, B\&G showed three were ineligible, one was mixed and nine found U-shapes mostly based on direct quotes from the paper's authors themselves. For example, GKJL1 classified Dolan et al. (2017) as a no despite this direct quote.

"the quadratic ' $U$-shape' observed in other research was also evidenced here across measures... It was observed without and with controls," (2015, p. 69).

So, after the misclassifications identified above were accounted for and ineligible studies dropped, B\&G found that 21 papers found $U$-shapes as several of the papers produced both longitudinal and cross-section estimates, four had 'mixed' results and there were zero 'no's'?.

\footnotetext{
7 Of the 'mixed papers Steptoe et al (2015) found U-shapes in high income countries without controls; Xing and Huang (2014) used three different measures of wellbeing and with one of them they "found an
} 
It is notable that the evidence from papers that used both longitudinal and cross-section data were both supportive of U-shapes. Misclassification errors alone meant GKJL1's conclusions were flawed. In addition, B and G noted that GKJL1 had omitted what is now 388 additional papers that all found well-being U-shapes in age which means their review was entirely unrepresentative of the findings in a voluminous literature ${ }^{8}$.

1) 168 papers published in peer reviewed journals in English 2013-2019 that involved GKJL1's criteria.

2) 88 papers in peer reviewed journals published in 2020, 2021 or are forthcoming.

3) 35 papers published over the period 2019-2021 as a book, book chapter, thesis or working paper.

4) 97 papers in peer-reviewed journals in English published pre-2013.

Thus, in addition to the 21 papers that $\mathrm{B} \& \mathrm{G}$ identified, that found $\mathrm{U}$-shapes, then, there are 388 more, making 409 in all, and counting'.

Galambos et al., (2021a, 2021b)—-henceforth GKJL2-in a reply to our comment, had the opportunity to respond to these omissions but instead responded, for reasons that remain unclear, that it was not their intention to do an exhaustive review.

"We referenced previous studies on life satisfaction and happiness and reviewed a sample of 29 relevant empirical studies published in peer-reviewed journals between 2013 and $2019^{10}$. It was not the goal of our paper to do an exhaustive literature review or meta-analysis, and to tally up the total number of studies that found, or did not find, the $U$ shape. Instead, we wanted to show support for the view that not all researchers find the $U$ shape, and when they do, they often also illustrate variability in age related patterns of happiness. We concluded that the $U$ shape is not as generalizable or robust as often portrayed."

And later:

"More importantly, we hold that what matters most for understanding happiness across the lifespan is not the number of studies that support one position but the fact that there are a variety of outcomes and conclusions." The evidence that we present does not support this statement.

GKJL2 have not credibly countered the evidence of clear U-shapes in these papers. When given the opportunity to produce an additional list of papers that did not find U-shapes to counter the 380 that did, GKJL2 reported none. They also did not challenge the findings of a single one of the 359 additional papers that $\mathrm{B} \& \mathrm{G}$ identified as inconsistent with their contentions ${ }^{11}$.

\footnotetext{
Footnote 7 (continued)

approximate $U$-shape" in age with a low point at age 45-49. Lachman et al. (Lachman, 2015) says "The MIDUS study data are consistent with ...the U-bend trend for life satisfaction."

8 The list is continually being updated as more papers are found. See here https://sites.dartmouth.edu/blanc hflower/.

9 These 409 papers are listed in Appendix A.

10 There were 28 not 29 studies as five of the thirty-three studies were reported twice.

11 It has come to our attention that the Galambos et al., (2021a, 2021b) paper was accepted based on the recommendation of two referees who it turns out were not sent and hence did not read the Blanchflower and Graham (2021a, 2021b) critique. It is normally inappropriate to report on the reviewing process but in this case, what happened is so egregious it justifies full transparency. Here is the direct statement from one
} 
GKJL1 further suggested that it was inappropriate to examine evidence on the U-shape using cross section data. They claim that:

\section{"Regardless of whether a $U$ shape is found in cross-sectional data, people at different ages or in different age groups reporting different levels of happiness is not evidence of a developmental process that takes place within individuals across the life span. Longitudinal research is needed to investigate intraindividual change."}

This seems extreme especially given the problems of attrition bias in longitudinal surveys. GKJL2 go further and unusually criticize cross-section studies because of their failure to include dead people. Cross-section studies, they argue,

"have selection issues. The pool of respondents at different ages for cross-sectional studies is inherently biased as, for example, those at older ages who have died are no longer available for inclusion in the study."

Nationally representative cross-section studies of people who are alive are not intended to be representative of dead people. Inevitably the unemployment rate calculated by the Bureau of Labor Statistics from a representative sample of the workforce in the US in April 2021 by construction does not include the labor force activity of the dead. The Census Bureau does however provide detailed data of who died as well as their characteristics.

Some of the 408 studies used longitudinal data and some used cross-section. Both types of data provide useful and broadly equivalent evidence on U-shapes. The new Lancet Commission on Mental Health Task Force (Aknin et al., 2020) has recently published its first evidence on the impact of COVID19 using both cross-section and longitudinal data.

\section{"Considering repeated cross-sectional and longitudinal surveys in tandem is par- ticularly informative because the two methodologies have non-overlapping strengths and weaknesses. For instance, because longitudinal surveys track the same peo- ple over time, this strategy minimizes concerns that different types of people were recruited for each survey, and that individual differences (e.g., personality) might obscure relationships in the data. Meanwhile, repeated cross- sectional data mini- mizes worries that respondents who drop out of the study systematically differ from those who remain (i.e. selective retention) because each survey recruits a new but well- balanced sample. As such, consistent patterns observed across both types of evidence offer robust and convincing conclusions."}

This seems right.

There is also much new evidence from longitudinal surveys finding U-shapes that is entirely consistent with the cross-section evidence. A paper that recently appeared in Psychological Medicine that examined the most important longitudinal studies in the worldthe 1946, 1958 and 1970 British cohort studies-finds inverted U-shapes in unhappiness and distress.

\section{Footnote 11 (continued)}

of the reviewers. "It would have been nice to see the $B$ \& $G$ paper, so as to better evaluate the Galambos et al. response. That said, I have a pretty good idea of what $B$ \& $G$ said in their article. I agree with everything Galambos et al. say in their very thoughtful piece. All of their points are valid ones.... More power to Galambos et al. for taking them on".

It is unusual to say the least for referees to guess what is in a paper. That means both referees were unaware of the misclassifications and the additional 388 papers that found U-shapes many of which were identified in B\&G missed by GKJL1. Having a "pretty good idea" is not good enough. We asked for a right of reply to this paper, but this was declined by the editor. See also Blanchflower (2021). 
"Overall, after controlling for cohort differences, the age profile of psychological distress followed an inverted $U$-shape in adulthood, with symptoms increasing from early-to mid-adulthood, and subsequently declining." Gondek et al (2020).

Prior, Jones and Manley (2020) use longitudinal data from the BHPS for Great Britain and find that "mental ill-health worsens over time from young adulthood to around the age of 50 , improving till around retirement age ( 65) where it appears to decline through old age:" An inverted U-shape in unhappiness.

The U.S. looks a bit different in the raw data than many other countries. In raw data, especially the happiness data from the General Social Survey, there is an uptick in wellbeing initially to around age thirty before it drops and the picks up again (Blanchflower \& Oswald, 2019) ${ }^{12}$ Blanchflower and Graham (2021b) note the importance of marriage in explaining this uptick which is present for the married but not the unmarried in the U.S. The U.S. stands out compared to European countries in terms of its earlier average age for married, and then high rates of divorce later, which in part explains the early uptick and then drop.

We now turn to a question that has been examined in the literature, whether control variables should or should not be included when examining the U-shape.

\subsection{To Control or Not to Control?}

Jebb, Morrison, Tay and Diener (2020)—henceforth JMTD—examined age and three measures of well-being, using data from the 2005-2016 Gallup World Poll (GWP). JMTD look at unadjusted, raw patterns in the data, yet compare those to general patterns from regressions with a battery of socio-economic controls in papers such as Blanchflower and Oswald (2008) and Graham and Ruiz- Pozuelo (2017).

As such, they are not comparing like with like. Each of these specifications captures different things. Specifications with controls capture the pure effects of aging, controlling for the confounding well-being effects of things that may change as people age. The specification without controls captures the effects of aging and these confounding factors. Neither specification is right or wrong, rather they are addressing different questions, something we will explore in greater detail below on whether to include controls or not.

Several authors, in addition to JMTD, such as Glenn (2009), have argued against the inclusion of control variables. Easterlin (2011) and Deaton (2018) have also made the case that the well-being effects of aging should be analyzed without controlling for confounding factors. Whether we include controls or not, we still find significant evidence of U-shapes in well-being and hill-shapes in stress. Stone, Schwarz, Deaton and Steptoe (2010) reported U-shape relations, using the 2008 GWP with and without controlsfor employment, having a partner and/or a child at home-in happiness and enjoyment, with a nadir around 50, a peak in worry at around 50, and in life satisfaction at the same age for men and women. Bittman (2021) finds U-shapes without controls for 43 countries.

There is a separate issue, though, which is what question each specification (with and without controls) is addressing. As noted above there are two broad ways to analyze the paper's scientific issue within this cross-section tradition. Blanchflower and Oswald (2019) noted that "it is not natural to see either approach as the 'right' or 'wrong'

\footnotetext{
12 In the raw data in the GSS if we score happiness on a 1-3 scale, happiness by age is as follows $18=2.09$; $19=2.10 ; 20=2.12 ; 21=2.12 ; 23=2.14 ; 25=2.17 ; 26=2.16 ; 27=2.18 ; 28=2.21 ; 29=2.21 ; 30=2.18$; $31=2.1732=2.21 ; 33=2.22 ; 34=2.22 ; 39=2.19 ; 43=21.7$ etc.
} 
one". The reason is that they measure different things. In this paper we present results both ways. One set of writings has attempted to study raw numbers on well-being and age-a descriptive approach. A second, including Blanchflower and Oswald (2008), has examined the patterns in regression equations for well-being, a ceteris-paribus analytical approach. The latter kind of methods are standard in epidemiology and economics, where the tradition has been to try to understand the impact of an independent variable (smoking, income, etc.) after adjusting for other influences on the dependent variable.

The descriptive approach measures the 'total', or reduced-form, effect of age. In contrast, the ceteris-paribus analytical approach measures the marginal effect of age after controlling for other socio-economic influences. For example, as people move from their $20 \mathrm{~s}$ to their $50 \mathrm{~s}$, they typically become richer. Say, for illustrative purposes, they also become happier. The descriptive approach would then ascribe the possible rise in their happiness over that period as due to age. The analytical approach would divide the possible rise in happiness into two components-that coming from income per se and any residual effect from ageing per se.

Blanchflower and Oswald (2009) gave the example of the relation between smoking and the probability of lung cancer. One set of estimates would look at the raw relation between smoking and disease probability, while the second adjusted for smoking plus diet, education, income and exercise. Compared to non-smokers, smokers tend to have worse diets and less education, income, and exercise. Thus, Blanchflower and Oswald argue, and we concur, "if the aim is to describe the data, it is reasonable to leave out most or all control variables. "Smokers die at rate Z'" is an acceptable statement to make. But that is not the same as "smoking changes your risk by Z'. It would be an error to use the unadjusted equation to tell the public what smoking does to their health."

There is a comparable issue in wage analysis. Assume a comparison of whether public sector workers are paid more than comparable private sector workers. We used 2019 Merged Outgoing Rotation Group Current Population Survey data, which is used to calculate a host of U.S. labor market variables (http://data.nber.org/cps/), and regressed log weekly earnings only on a public sector variable for a sample of 154,512 workers. The public sector variable has a statistically significant and positive with a coefficient of +0.1533 with a t-statistic of 27 . This shows that public sector workers earn more than private sector workers. Yet public sector workers are more qualified than private sector workers, so it is appropriate to control for highest grade of education completed. Including a set of highest education variables as controls, the public sector variable becomes negative with a statistically significant negative coefficient of -0.0212 and a t-statistic of 4.

The adjusted R-squared in the first equation is 0.0046 in the first 0.1728 in the second, which means adding the education variables improves the fit of the equation. The higher pay of public sector workers in the raw data is attributable to their education, revealed by including controls, not to working in the public sector. Both sets of estimates, with and without controls, are useful and tell us different things.

Below we show that the Office of National Statistics (ONS) in the UK publishes raw estimates of well-being variables as well as ones from regression equations with sets of controls using cross-section data. Both are useful.

In what follows we report estimates with and without controls to determine to what extent they make a difference on 3.5 million people. We look at micro-data on three different measures of happiness-4-step and 11-step life satisfaction, Cantril's 11-step life satisfaction ladder using three major surveys - the Eurobarometers (1980-2019), 


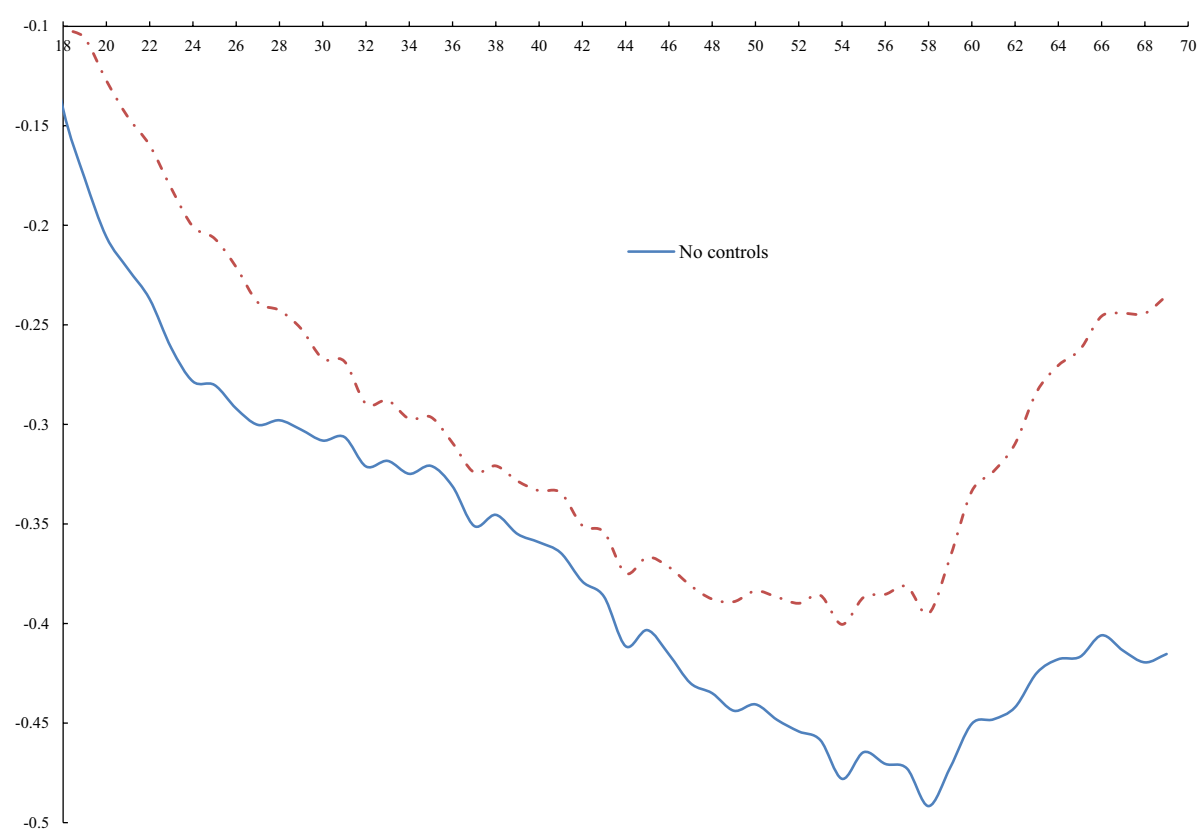

Fig. 1 Eurobarometer Life Satisfaction Regression Coefficients, 2009-2019

the Gallup World Poll (2005-2019) and the Annual Population Survey for the UK from 2016-2019. We find widespread evidence of U-shapes in well-being whether controls are included or not. We also look at recent evidence for the US on anti-depressant medications as a validation of the happiness data, using data from the US Census Bureau for 2021, which traces out an inverted U-shape in age.

Hudomiet, Hurd and Rohwedder (2021) from the Rand Corporation used longitudinal data from the US Health and Retirement Survey (HRS) and confirmed that life satisfaction rose from around age 50 to sixty-five, consistent with findings of U-shapes. "We pooled the 2008-2016 HRS waves to find average life satisfaction by age from age 51 to 89 (Fig. 1). The patterns are consistent with the literature in that life satisfaction monotonically increases after age 51. The increase is steepest between age 57 and 65 around the time when most individuals retire. After age 65 the increase is more modest, from 3.89 at age 65 to about 3.96 at age 89, a statistically significant increase:" another U-shape. They show that after age sixty-five, once mortality selection bias is adjusted for, life satisfaction declines after the U-shape. In our empirical analysis, we largely restrict our analysis to under age seventy. 
Table 173 studies in social indicators research finding U-shapes in wellbeing by country and group

Single countries

1. Australia-Ambrey \& Fleming (2014), Chesters, Simona \& Suder (2021), Li (2016) Perales (2016)

2. Belgium-Hooghe \& Vanhoutte (2011)

3. Canada-Bonikowska et al. (2014), Latif (2016)

4. China - Cheng (2014), Churchill \& Mishra (2017), Fang (2017), Gao, Meng \& Zhang (2014). Huang (2019), Lam \& Liu (2014), Mishra et al. (2014), Smyth, Nielsen \& Zhai (2010), Steele and Lynch (2013), Sun \& Xiao (2012), Tani (2017), Wang \& Vanderweele (2011), Wu \& Tam (2015), Xing and Huang (2014), Zhou \& Yu (2017)

6. Germany-Bartolini, Bilancini \& Sarracino (2013), Becchetti et al. (2012), Brockmann (2010), Gwozdz and Sousa-Poza (2010), Mertens \& Beblo (2016), Obućina (2013), Pagán-Rodríguez (2015)

7. Iceland-Gudmundsdottir (2013)

Indonesia-Sohn (2016)

8. Italy Ferrante (2017)

9. Japan - Tiefenbach \& Kohlbacher (2014), Tsai (2021), Yamamura et al. (2015)

10. Luxembourg-Sarracino (2014)

11. North Cyprus-Gokdemir \& Tahsin (2014)

12. South Korea-Ha \& Jang (2015), Ha \& Kim (2013), Tsai (2021)

13. Spain-Cuñado \& de Gracia $(2012,2013)$

14. Switzerland-Chesters, Simona \& Suter (2021)

15. Taiwan-Chang (2013), Liao, Shaw \& Lin (2015), Tsai (2021)

16. UK-Baird, Lucas \& Donnellan (2010), Bartram (2021), Blanchflower, Oswald \& Stewart-Brown (2013), Downward \& Dawson (2016), McAdams, Lucas \& Donnelann (2012), Mertens \& Beblo (2016), Tumen \& Zeydanli (2014)

17. Uruguay-Gandelman \& Piani (2013)

18. USA - Davis \& Wu (2014), Dolan, Kurdna \& Stone (2017), Helliwell \& Wang (2014), Kapteyn et al. (2015), Okulicz-Kozaryn \& Mazelis (2017)

\section{Groups of countries}

19. Transition economies-Amini \& Douarin (2020), Habibov \& Afandi (2015), Glatz \& Ede (2020)

20. European countries - Albiol-Sanchez et al. (2020), Artés et al. (2014), Başlevent \& Kirmanoğlu (2014), Georgellis et al. (2009), Gimenez-Nadal \& Sevilla-Sanz (2011); Gokdemir \& Tahsin (2014), Kirmanoğlu

\& Başlevent (2014), Perales (2016), Piper (2015), Pittau et al. (2010), Samuel \& Hajdar (2016)

21. Asian countries - Ngoo, Tey \& Ta (2015), Trung et al. (2013)

22. World-Ball \& Chernova (2008), Olgiati, Calvo \& Berkman (2013), Rözer \& Kraaykamp. (2013), Salinas-Jiménez et al. (2011)

References are in Appendix A

\section{Seventy-Three Studies Published in Social Indicators Research Finding U-shapes in Age in Wellbeing}

As background we start in Table 1 by summarizing 73 studies that we identified that were published in Social Indicators Research that found U-shapes in age in well-being. In most cases this involved finding both age and age squared terms to be significantly different from zero, with a negative and a positive coefficient respectively, in well-being equations.

Of these 73 studies GKJL1 identified only four papers examining U-shapes from Social Indicators Research. Blanchflower and Graham (2021a) noted that of these, based on direct quotes from the papers Dolan et al. (2017) was wrongly classified by GKJL1 as not finding U-shapes when it did. Xing and Huang (2014) were classified as a 'no' when, it should 
have been classified as having found a U-shape. Ferrante (2017) and Li (2017) were classified as 'mixed' findings, but they also found U-shapes based on the authors own published statements.

There were 53 additional papers in Social Indicators Research that fitted the GKJL1 criteria of being published in a peer-reviewed journal in English between 2013 and 2019 that they didn't include in their survey. It remains unclear why they didn't identify these papers. Sixteen were published in Social Indicators Research from 2008-2012 and four were published in 2020 and 2021.

Table 1 shows that twenty papers focused on multiple countries. U-shapes were found in nineteen distinct countries ${ }^{13}$. There are fifteen papers that found U-shapes for China; seven for the UK and six for Germany. Thus, even in the papers published in this journal (Social Indicators Research), the evidence of U-shapes is generalizable and robust. It is unclear why GKJL1 and GKJL2 missed these 68 papers $^{14}$.

\section{Eurobarometer Surveys}

As noted earlier several studies of well-being in the psychology literature cited Inglehart (1990) as not finding a U-shape in happiness. Inglehart reported U-shapes in happiness in nine of the sixteen countries examined in his Tables 7.3-7.5. He used data from Eurobarometer \#13-\#26 (April 1980-November 1986) on twelve European countries. These data are available in the Mannheim trend file and so in Table 2 we report three sets of estimates. First, we examine life satisfaction as reported in his Table 7.3-this is the standard Eurobarometer 4-step question $(\mathrm{n}=97,970)$.

Q1. On the whole, are you very satisfied, fairly satisfied, not very satisfied or not at all satisfied with the life you lead? Very satisfied=4; Fairly satisfied=3; Not very satisfied $=2$; Not at all satisfied $=1$. We then turn to 3-step happiness which has half as many observations $(\mathrm{n}=49,836)$.

Q2. Taking all things together, how would you say things are these days-would you say you're very happy $=1$, fairly happy $=2$ or not too happy-3 these days?

In part 1) of the table we report on the results of estimating country level equations with the same data that contains year dummies plus age and its square. We also report an overall equation that includes country dummies that has a midpoint of 47 there are significant U-shapes in $9 / 12$ countries. Adding controls in part 2) there are significant U-shapes in all twelve. We then go to part 3) when we use the happiness variable with controls and there are U-shapes in all twelve again. To get a sense of the scale of the drop, in the raw data life satisfaction was 3.24 at age 15 falling to 2.95 at age 48 . Being married had an average score of 3.08 versus 2.93 for widowed, so the drop, in life satisfaction to midlife was double the drop from losing a spouse. Hardly trivial.

\footnotetext{
${ }^{13}$ Chesters et al. (2021) produced somewhat mixed estimates for Australia and stronger ones for Switzerland while Tsai (2021) found U-shapes for South Korea, Japan and Taiwan. Baird et al. (2010) found strong evidence of a U-shape for the UK but weaker evidence for Germany.

14 We further identified 80 papers that found U-shapes in well-being, reported in the Appendix A, published in the Journal of Happiness Studies of which only two were identified by GKJL1 or GKJL2.
} 
Table 2 Inglehart (1990) redone, 1980-1986

\begin{tabular}{|c|c|c|c|c|}
\hline & Age & $\mathrm{Age}^{2}$ & Age Minimum & $\mathrm{N}$ \\
\hline \multicolumn{5}{|c|}{ 4-step Life satisfaction no controls } \\
\hline All & $-.0095(13.51)$ & $.0001024(13.55)$ & 47 & 97,970 \\
\hline France & $-.02511(11.45)$ & $.0002728(11.63)$ & 46 & 9,867 \\
\hline Belgium & $-.0109456(4.88)$ & $.000081(3.42)$ & 67 & 9,871 \\
\hline Netherlands & $-.0148594(7.40)$ & $.000154(7.16)$ & 48 & 10,149 \\
\hline Germany & $.003539(1.82)$ & $-.0000206(0.97)$ & & 10,110 \\
\hline Italy & $-.0094792(4.11)$ & $.0000978(3.82)$ & 48 & 10,760 \\
\hline Luxembourg & $-.002416(0.62)$ & .000058 (1.35) & & 2,965 \\
\hline Denmark & $-.00256(1.43)$ & $.0000185(1.01)$ & & 9,911 \\
\hline Ireland & $-.01138(4.90)$ & .0001576 (6.09) & 36 & 9,914 \\
\hline UK & $-.007349(3.91)$ & .000097 (4.87) & 38 & 13,493 \\
\hline Greece & $-.01217(4.19)$ & $.0001097(3.50)$ & 56 & 8,956 \\
\hline Spain & $-.03432(4.41)$ & $.000357(4.30$ & 48 & 985 \\
\hline Portugal & $-.02798(4.07)$ & $.000255(3.40)$ & 55 & 989 \\
\hline \multicolumn{5}{|c|}{ 4-step Life satisfaction with controls } \\
\hline All & $-.017208(18.68)$ & $.000202(20.52)$ & 43 & 97,970 \\
\hline France & $-.01722(5.90)$ & $.000197(6.19)$ & 44 & 9,867 \\
\hline Belgium & $-.02078(7.33)$ & $.000199(6.65)$ & 52 & 9,871 \\
\hline Netherlands & $-.02237(8.39)$ & $.00025(8.75)$ & 45 & 10,149 \\
\hline Germany & $-.006262(2.42)$ & $.000085(3.09)$ & 36 & 10,110 \\
\hline Italy & $-.02299(7.22)$ & $.000246(7.20)$ & 47 & 10,760 \\
\hline Luxembourg & $-.0204(3.88)$ & $.000273(4.85)$ & 37 & 2,965 \\
\hline Denmark & $-.00995(4.12)$ & $.00012(4.88)$ & 41 & 9,911 \\
\hline Ireland & $-.014199(4.71)$ & $.000208(6.27)$ & 34 & 9,914 \\
\hline UK & $-.01376(5.75)$ & $.000188(7.31)$ & 36 & 13,493 \\
\hline Greece & $-.0242(6.26)$ & $.000244(5.98)$ & 50 & 8,956 \\
\hline Spain & $-.0475(4.53)$ & $.000481(4.51)$ & 49 & 985 \\
\hline Portugal & $-.0270(2.66)$ & $.000264(2.66)$ & 51 & 989 \\
\hline \multicolumn{5}{|c|}{ 3-step Happiness with controls } \\
\hline All & $-.01627(15.25)$ & $.000169(14.83)$ & 48 & 49,836 \\
\hline France & $-.01623(4.82)$ & $.000143(3.92)$ & 51 & 4,889 \\
\hline Belgium & $-.01552(4.78)$ & $.000139(4.02)$ & 58 & 4,920 \\
\hline Netherlands & $-.02539(7.46)$ & $.00026(7.15)$ & 60 & 5,097 \\
\hline Germany & $-.00585(1.89)$ & $.000064(1.95)$ & 49 & 4,972 \\
\hline Italy & $-.03048(8.77)$ & $.00029(7.84)$ & 49 & 5,159 \\
\hline Luxembourg & $-.00965(1.46)$ & $.000126(1.75)$ & 53 & 1,465 \\
\hline Denmark & $-.01376(3.55)$ & $.00013(3.36)$ & 40 & 4,790 \\
\hline Ireland & $-.0122(3.53)$ & $.000166(4.35)$ & 53 & 4,963 \\
\hline UK & $-.00834(2.89)$ & $.000109(3.51)$ & 38 & 6,690 \\
\hline Greece & $-.0205(5.56)$ & $.000206(5.27)$ & 42 & 4,928 \\
\hline Spain & $-.0271(3.55)$ & $.00025(3.17)$ & 51 & 978 \\
\hline Portugal & $-.0051(0.76)$ & $.0004(0.61)$ & 54 & 985 \\
\hline
\end{tabular}

Eurobarometers \#13-26. T-statistics in parentheses 


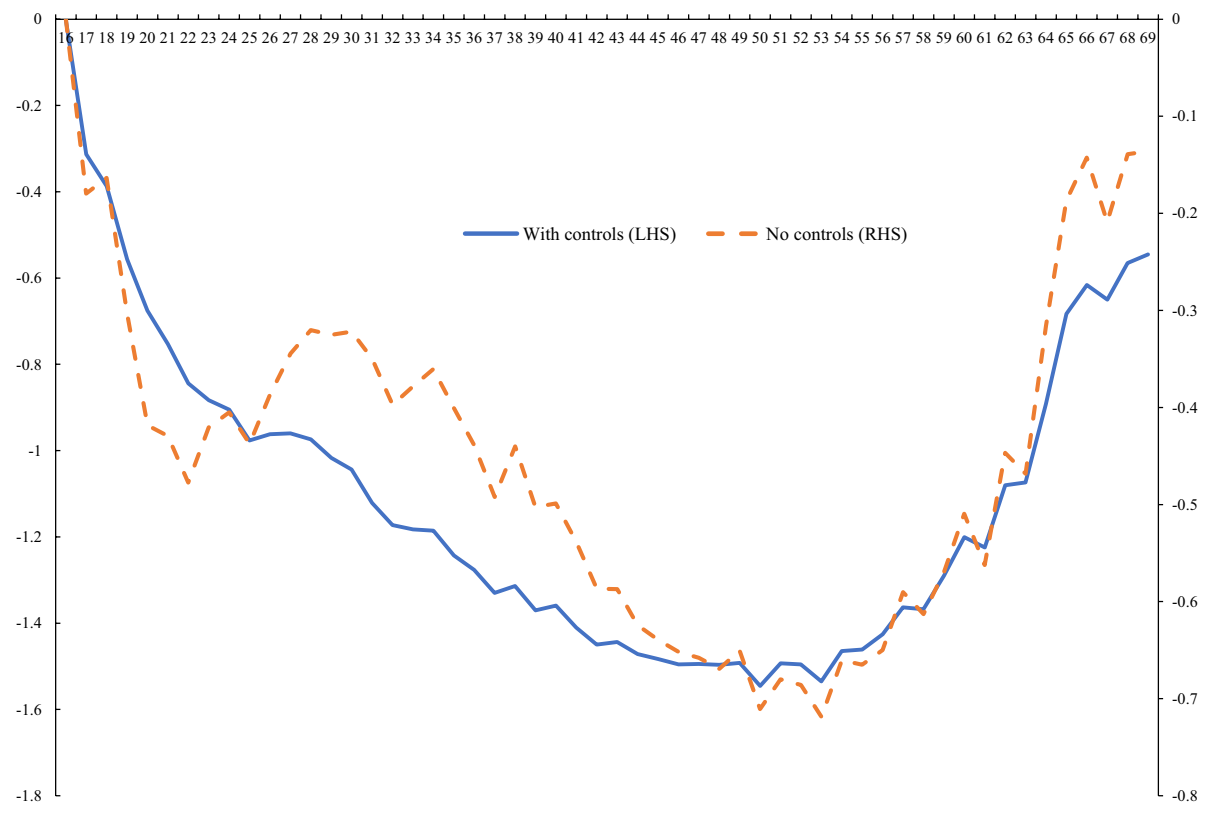

Fig. 2 UK Life Satisfaction Regression Coefficients, 2016-2019

Diener and Suh (1998) cite work by Okma and Veenhoven (1996), henceforth OV that does not seem to have ever been published and we have not been able to find a copy, but which according to Diner and Suh also used the Eurobarometer for 8 nations in the Eurobarometer between 1980 and 1990. They argue that Okma and Veenhoven "showed an almost flat line with age. From around age 18 to 90 there was almost no change in life satisfaction". So, we went back to analyze these same Eurobarometer files for 1980 through 1990 which are also part of the publicly available Mannheim Trend file. They cover Eurobarometer \#13 through \#34.1, noting that not all the surveys over this period contain the life satisfaction question. It is unclear which eight nations were the focus of the OV study, so we examine nine nations for which there are at least 20,000 observations over this time period-France; Belgium; Netherlands; Germany; Italy; Denmark; Ireland: UK and Greece so there are 207,558 observations in total ${ }^{15}$. The life satisfaction question is the same as that used in Q1 above.

Across these nine nations the average score for those under 20 was 3.14, reaching a low point of.

2.97 at age 54 and then rising to 3.20 at age 90 . It is true that life satisfaction scores at age 90 are not that different from age 18 but that ignores the midlife drop. Without out controls there is a well-defined nadir in well-being in age controlling for year and nation that minimizes at age 48 and also one with controls - for gender, education, marital and labor force status - that minimizes at age 43.

$\overline{15}$ Diener and Suh claim there were 300,000 observations but we were unable to confirm that. 


\begin{tabular}{lllll}
\hline & Age & Age $^{2}$ & Minimum & N \\
\hline No controls & $-0.009752(20.50)$ & $0.000101(19.74)$ & 48 & 207,363 \\
With controls & $-0.015258(24.58)$ & $0.000176(26.66)$ & 43 & 207,363 \\
\hline
\end{tabular}

It seems then that Diener and Suh (1998) were incorrect, claiming there was a flat line in age from age 18 to 90 across these nations. The decline in life satisfaction from under 20 to age 48 of 0.17 is about the same as a fall in life satisfaction of 0.16 from married (3.10) to widowed (2.94). Not trivial.

Finally, we examined a pooled Eurobarometer files from 2009-2019 used in Blanchflower and Clark (2019) with around 1 million observations covering 37 European countries. We estimated life satisfaction regressions which included single year of age dummies as well as year and country dummies. In Fig. 1 we plotted these results and then we reestimated adding controls for gender, education, labor force and marital status. There are U-shapes with and without controls.

GKJL2 suggested that they had become aware of additional relevant studies, including ones that used Eurobarometer data.

"Morgan and O'Connor (2017), for example, reported an M shape in Eurobarometer life satisfaction data. Recently, they argued "...the U-shaped relation is, in fact, not everywhere” (Morgan \& O'Connor, 2020, p. 201)."

Interestingly GKJL2 once again misrepresented what Morgan and O'Connor (2020) showed. They also failed to note that in a published response to that exact paper Blanchflower (2020a) showed that the M-shape arises because of the exclusion of happy students ${ }^{16}$. Once the students are included the U-shape reappears. Morgan and O'Connor (2020) concur. "However, we agree with Blanchflower that the M-shape arises in the general population of our study as a result of excluding students from the sample." GKJL2 also ignored the Morgan and O'Connor's (2020) conclusion. "While we may presently describe the evidence differently than Blanchflower, this distinction is not so large. If in his recent work Blanchflower (2020b), he concluded psychological well-being generally reaches a minimum in midlife, rather than the U-shape is everywhere, we would have had a hard time disagreeing. "QED.

\section{Gallup World Poll, 2005-2019}

JMTD examined data from the Gallup World Poll (GWP)and bunch countries into ten unusual regions, nesting each country within a region and fixing age over the lifespan as the same for each country in the group. This introduces bias as there are different age effects by country and they find limited U-shapes. We estimate a more flexible form where age and year effects are allowed to vary by country, as do our controls. In all four sets of equations there are major differences by country not revealed in JMTD's analysis. The GWP data file we analyze has $2,017,774$ observations and 168 countries. We estimated $168 * 4$ separate

\footnotetext{
16 GKJL2's inability to cite the Blanchflower response in the same volume pointing this out is rather surprising given that in the title of the Morgan and O'Connor (2020) paper it says "..A response to Blanchflower.".
} 
Table 3 Estimates of Minima/Maxima-158 countries

\begin{tabular}{|c|c|c|c|c|}
\hline & \multicolumn{2}{|c|}{ Life satisfaction } & \multicolumn{2}{|l|}{ Stress } \\
\hline & No controls & Controls & No controls & Controls \\
\hline All & 75 & 58 & 43 & 44 \\
\hline Afghanistan & & & 54 & 48 \\
\hline Albania & 58 & 51 & 53 & 52 \\
\hline Algeria & & 49 & 53 & 52 \\
\hline Angola & & & & 47 \\
\hline Argentina & 65 & 58 & 44 & 44 \\
\hline Armenia & & & 68 & 60 \\
\hline Australia & 40 & 46 & & \\
\hline Austria & & 69 & & \\
\hline Azerbaijan & & 54 & 53 & 46 \\
\hline Bahrain & 55 & 43 & 48 & 46 \\
\hline Bangladesh & 55 & 45 & 58 & 60 \\
\hline Belarus & & & 38 & 37 \\
\hline Belgium & 54 & & & \\
\hline Belize & & & 45 & 39 \\
\hline Benin & 68 & & 49 & 47 \\
\hline Bolivia & 66 & 61 & 54 & 61 \\
\hline Bosnia and Herzegovina & & 68 & 49 & 51 \\
\hline Botswana & & & 47 & 70 \\
\hline Brazil & 53 & 50 & 35 & 34 \\
\hline Bulgaria & & 69 & 46 & 46 \\
\hline Cambodia & 62 & 47 & 57 & 54 \\
\hline Cameroon & 64 & 59 & 52 & 58 \\
\hline Canada & 29 & 45 & & \\
\hline Chile & & 68 & 44 & 43 \\
\hline China & 52 & 50 & & \\
\hline Colombia & 62 & 56 & 45 & 44 \\
\hline Congo (Kinshasa) & & & 52 & 54 \\
\hline Congo Brazzaville & & 61 & & \\
\hline Costa Rica & 59 & 56 & 33 & 27 \\
\hline Croatia & & & 45 & 49 \\
\hline Cuba & & & 39 & \\
\hline Cyprus & 65 & 55 & 42 & 27 \\
\hline Czech Republic & & & 34 & 28 \\
\hline Denmark & & 44 & & \\
\hline Dominican Republic & 58 & 58 & 44 & 46 \\
\hline Ecuador & & 69 & 53 & 59 \\
\hline Egypt & 53 & 44 & 48 & 47 \\
\hline El Salvador & 67 & 62 & 49 & 52 \\
\hline Estonia & & 60 & 47 & 46 \\
\hline Ethiopia & 55 & 42 & 67 & \\
\hline Finland & & 58 & & \\
\hline France & & 59 & & \\
\hline
\end{tabular}


Table 3 (continued)

\begin{tabular}{|c|c|c|c|c|}
\hline & Life satisfac & & Stress & \\
\hline & No controls & Controls & No controls & Controls \\
\hline Gabon & & 66 & & \\
\hline Georgia & & 70 & & 68 \\
\hline Germany & & 64 & & \\
\hline Ghana & 55 & 49 & 55 & 56 \\
\hline Greece & & 64 & 50 & \\
\hline Guatemala & 69 & 65 & 50 & 54 \\
\hline Guinea & 47 & & 59 & 58 \\
\hline Guyana & & & 49 & \\
\hline Haiti & & 52 & 56 & 54 \\
\hline Honduras & 65 & 60 & 53 & 58 \\
\hline Hong Kong & 66 & 66 & & \\
\hline Hungary & 69 & 59 & 40 & 38 \\
\hline Iceland & 57 & 51 & & \\
\hline India & & & 65 & \\
\hline Indonesia & 59 & 35 & 37 & \\
\hline Iran & 61 & 55 & 46 & 48 \\
\hline Iraq & & 47 & 53 & 55 \\
\hline Ireland & 43 & 48 & & \\
\hline Israel & & 69 & 47 & 48 \\
\hline Italy & & 64 & 27 & \\
\hline Ivory Coast & 56 & 49 & 48 & 61 \\
\hline Jamaica & 51 & 53 & 44 & 38 \\
\hline Japan & & 64 & & 29 \\
\hline Jordan & 54 & 48 & 51 & 51 \\
\hline Kazakhstan & 65 & 51 & 44 & \\
\hline Kenya & & & 57 & \\
\hline Kosovo & & 58 & 47 & 45 \\
\hline Kuwait & 38 & 37 & 42 & 40 \\
\hline Kyrgyzstan & 64 & 50 & 58 & 54 \\
\hline Laos Latvia & 38 & & & \\
\hline Latvia & & & 43 & 42 \\
\hline Lebanon & 65 & 60 & 50 & 51 \\
\hline Lesotho & 70 & 59 & 61 & 58 \\
\hline Liberia & & & 54 & 53 \\
\hline Libya & 42 & 42 & 37 & 39 \\
\hline Lithuania & & 68 & 46 & 48 \\
\hline Luxembourg & & 52 & 36 & 33 \\
\hline Macedonia & 69 & 62 & 51 & 52 \\
\hline Madagascar & 51 & 44 & 49 & 49 \\
\hline Malaysia & & 48 & & \\
\hline Mali & 70 & 42 & & \\
\hline Malta & 62 & 53 & 31 & 29 \\
\hline Mauritania & & & 52 & \\
\hline
\end{tabular}


Table 3 (continued)

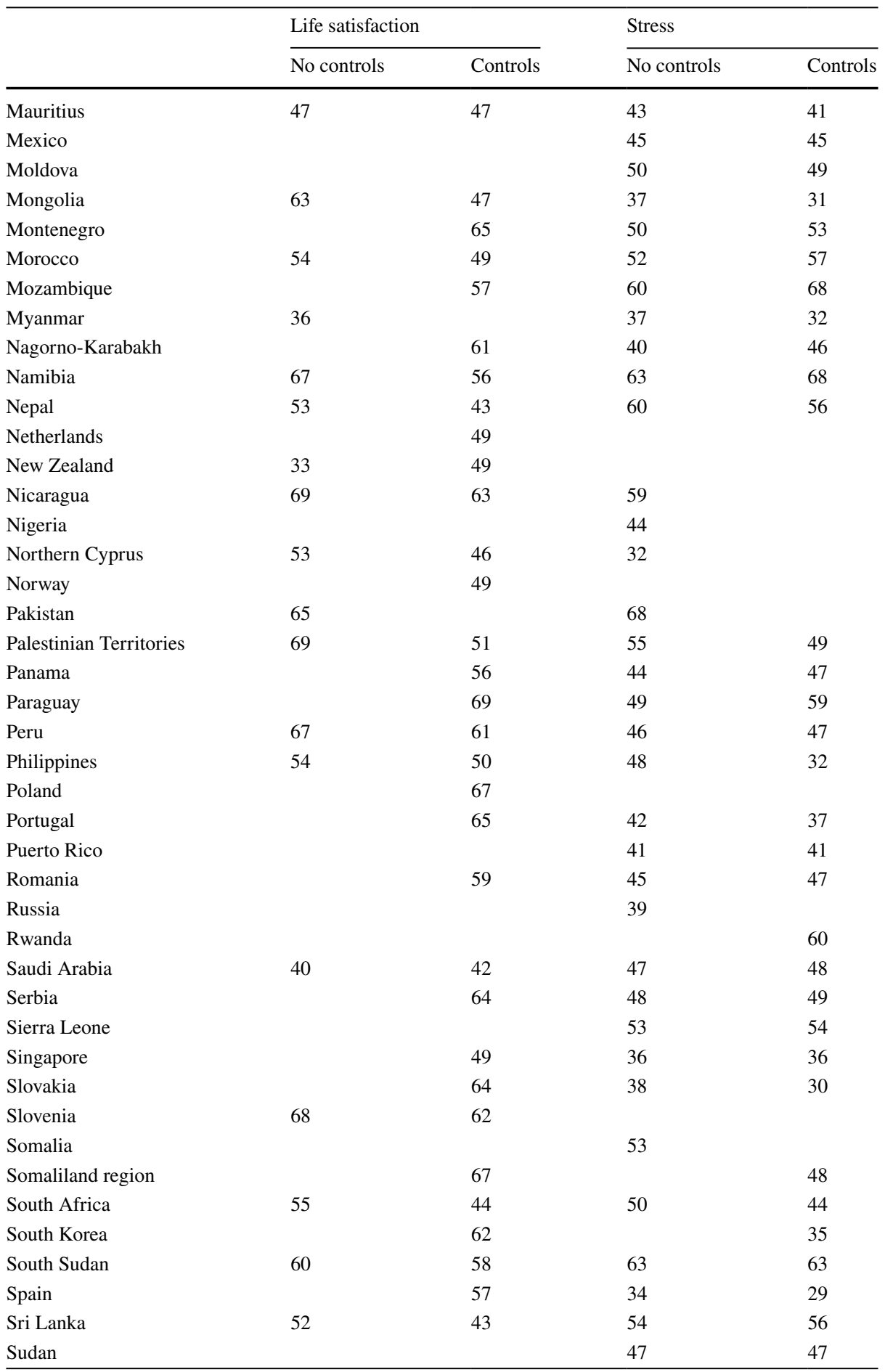


Table 3 (continued)

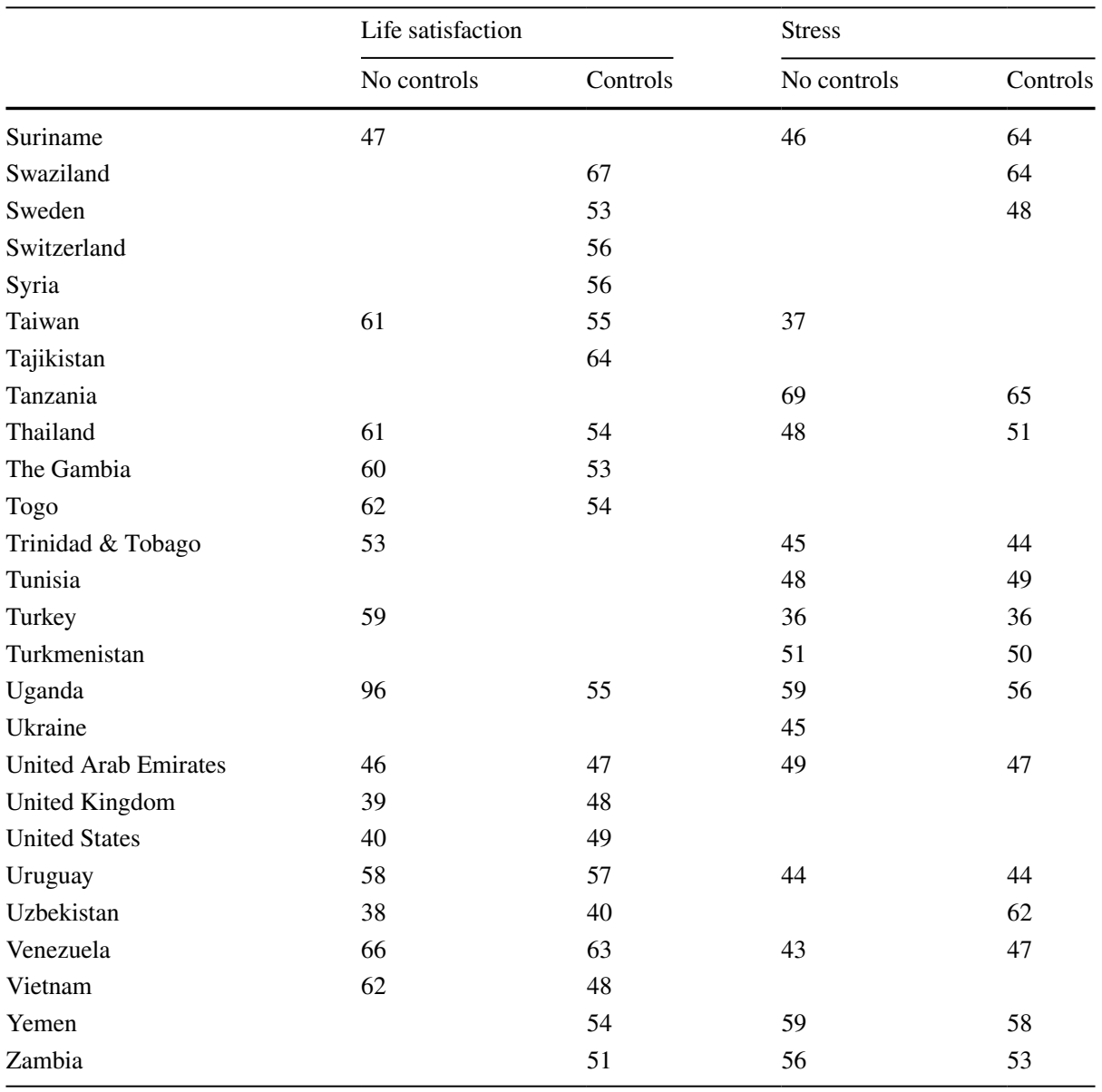

OLS estimates; 'no controls' includes year dummies and 'all' equation also has 167 country dummies. Controls includes dummies for gender, education, and marital and labor force status. Minima/Maxima calculated by differentiating the age and age 2 terms with respect to age and solving

Gallup World Poll 2005-2019

country level equations, including age and age squared terms and then added controls for gender, marital and labor force status and education for pain, stress and life satisfaction.

The questions used are as follows:

Q3. Cantril's ladder. "Please imagine a ladder, with steps numbered from 0 at the bottom to 10 at the top. The top represents the best possible life for you and the bottom of the ladder represents the worst possible life for you. On which step of the ladder would you say you personally feel you stand at this time?".

Q4. Stress. "Have you experienced stress yesterday?"

We found significant U-shapes in life satisfaction and hills in stress in one or more of the four sets of results in 155 countries (Table 3), averaging at age 51. For life satisfaction without controls we found a significant U-shape in 76 countries and in 118 with controls. In the case of stress, there were hill shapes in 116 and 107 countries respectively. 
Table 4 Well-being by age in the UK from the Annual Population Survey, 2011-2017 (averaged)
Table 5 Coefficients and $\mathrm{t}$-statistics in age in well-being equations for the UK from the ONS

\begin{tabular}{lllll}
\hline Age & Life satisfaction & Happiness & Worthwhile & Anxious \\
\hline $16-19$ & 7.90 & 7.62 & 7.76 & 2.71 \\
$20-24$ & 7.62 & 7.35 & 7.71 & 2.85 \\
$25-29$ & 7.66 & 7.41 & 7.72 & 2.84 \\
$30-34$ & 7.64 & 7.41 & 7.81 & 2.92 \\
$35-39$ & 7.52 & 7.34 & 7.82 & 3.04 \\
$40-44$ & 7.41 & 7.28 & 7.77 & 3.10 \\
$45-49$ & 7.32 & 7.19 & 7.70 & 3.15 \\
$50-54$ & 7.29 & 7.18 & 7.65 & 3.21 \\
$55-59$ & 7.37 & 7.27 & 7.68 & 3.17 \\
$60-64$ & 7.63 & 7.53 & 7.80 & 2.91 \\
$65-69$ & 7.87 & 7.81 & 7.98 & 2.64 \\
$70-74$ & 7.89 & 7.81 & 8.10 & 2.66 \\
$75-79$ & 7.84 & 7.74 & 8.06 & 2.66 \\
$80-84$ & 7.76 & 7.64 & 7.91 & 2.65 \\
$85-89$ & 7.66 & 7.54 & 7.69 & 2.66 \\
90 and over & 7.55 & 7.39 & 7.41 & 2.61 \\
\hline
\end{tabular}

Personal Well-being estimates by age and sex, September 2012-September 2017, ONS https://www.ons.gov.uk/peoplepopulationandc ommunity/wellbeing/datasets/personalwellbeingestimatesbyageandsex

\begin{tabular}{lllll}
\hline Age & Life satisfaction & Happiness & Worthwhile & Anxious \\
\hline $16-29$ & $.340(13.50)$ & $.158(4.99)$ & $.045(1.68)$ & $-.018(0.42)$ \\
$30-39$ & $.142(7.65)$ & $.058(2.42)$ & $.046(2.42)$ & $.014(0.43)$ \\
$50-59$ & $.034(1.81)$ & $.024(1.04)$ & $.018(0.98)$ & $-.102(3.15)$ \\
$60-69$ & $.199(7.92)$ & $.231(7.57)$ & $.254(10.24)$ & $-.237(5.61)$ \\
$70+$ & $.595(10.55)$ & $.590(8.33)$ & $.611(11.50)$ & $-.758(8.13)$ \\
\hline
\end{tabular}

Reference group: 40-49 and OLS. Controls are gender; ethnicity; migration status; highest qualification; marital status; Occupation; disability; health; housing tenure; religion and region

Well-being regression models based on Annual Population Survey data for Great Britain for the period October 2017-September 2018. Office of National Statistics. https://www.ons.gov.uk/peoplepopulatio nandcommunity/wellbeing/datasets/annualpopulationsurveyregressi onmodels

Contrary to JMTD's conclusion that "much about the U shape has been overblown" using the same data we find broad evidence of U-shapes with and without controls across many countries. This is consistent with findings in Blanchflower (2020a, 2020b).

\section{UK Annual Population Surveys, 2011-2020}

Table 4 reports official estimates of well-being by age as reported by the UK's Office of National Statistics (ONS), the UK's largest independent producer of official statistics and its recognized national statistical institute. It is responsible for collecting and publishing statistics related to the economy, population and society at national, regional, and local levels and also conducts the 
Annual Population Survey and release to the public the micro data that we use in this section. Data are available for four measures of well-being- life satisfaction; happiness; worthwhileness and anxiety. The first three of these shows declines through midlife with through from youth to the age group 50,054 and a subsequent pick up. The latter variable anxiety shows a rise to a peak also in the age group 50-54. Table 5 then reports the coefficients on a group of size age variables and a long list of control variables which also show a low point in the fifties for the first three well-being measures and a peak for anxiety. The ONS in the UK confirms there is a U-shape in the well-being data.

\subsection{The U-Shape is not Only Shown in Averages}

GKJL2 argue that: "mean levels alone, however, do not provide important information about variability in happiness at any given age." What matters they claim unusually, is something else.

"Emphasizing an average trend in happiness (if one could be found) is less important than discovering diversity in life paths and then identifying determinants of deviations from the average."

This is another red herring. It makes no difference whether we look at means or other parts of the distribution; the answer is the same: there are U-shapes. GKJL2's state that it is incorrect to conclude that the results from econometric analysis apply to every person, and that instead the focus should be on how individuals are different - "some people are stable, some increase, and some show a decrease in midlife". Yet without large $\mathrm{N}$ statistical analysis and then randomized controls trials that allow for the testing of different practices and policies in a range of settings, we would not have cures for cancer or successful vaccines.

In all cases a variable of interest has a mean and a distribution around it and there can be outliers which may or may not be important. That regularity does not assume that all outliers do not matter, it simply establishes the general patterns. That is the approach that economists also take to establish robust patterns as well as, when possible, the direction of causality. That is almost impossible to do with an $\mathrm{N}$ of 1 or even an $\mathrm{N}$ of 100. Ignoring robustly established empirical patterns and their implications-such as the U shape-and simply focusing on a few individuals and making generalizations, in our view, is a dangerous mistake and certainly not robust social science.

We illustrate this point with further analyses of life satisfaction using the APS data. The life satisfaction question was:

Q5. "Overall, how satisfied are you with your life nowadays-where nought is 'not at all satisfied' and 10 is 'completely satisfied?

17 .

The unweighted distribution of life satisfaction responses by age, comparing age 16 with the age minimum of the function at age 50 and age 70 .

\footnotetext{
17 The other 3 variable questions that give similar results as life satisfaction were as follows:

Overall, how happy did you feel yesterday-where nought is 'not at all happy' and 10 is 'completely happy?

Overall, to what extent do you feel that the things you do in your life are worthwhile? Interviewer instruction: where nought is 'not at all worthwhile' and 10 is 'completely worthwhile?'.

On a scale where nought is 'not at all anxious' and 10 is 'completely anxious', overall, how anxious did you feel yesterday?
} 


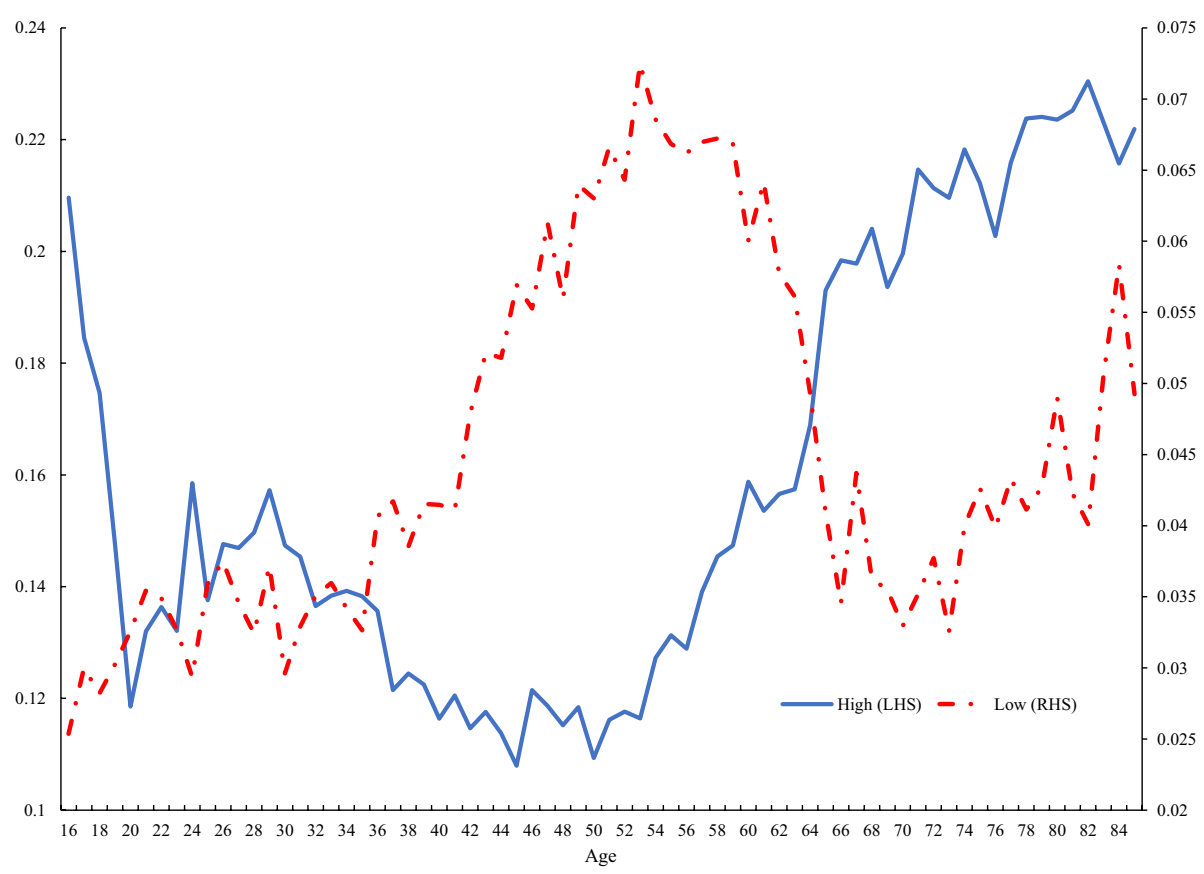

Fig. 3 High (=10) and Low (0-4) Life Satisfaction Scores. UK, 2016-2019

\begin{tabular}{llll}
\hline & Age 16 & Age 50 & Age 70 \\
\hline 0 & 0.13 & 0.87 & 0.46 \\
1 & 0.27 & 0.57 & 0.25 \\
2 & 0.27 & 1.06 & 0.57 \\
3 & 0.27 & 1.48 & 0.72 \\
4 & 1.60 & 2.32 & 1.29 \\
5 & 3.07 & 7.92 & 5.43 \\
6 & 5.61 & 7.98 & 5.19 \\
7 & 18.29 & 19.20 & 12.60 \\
8 & 29.24 & 33.86 & 33.16 \\
9 & 20.29 & 13.81 & 20.36 \\
10 & 20.96 & 10.93 & 19.96 \\
Mean & 8.11 & 7.43 & 8.03 \\
$\mathrm{~N}$ & 749 & 7,554 & 8,832 \\
\hline
\end{tabular}

Mean scores at age 51 are around two thirds of a log satisfaction point lower at age 50 than at age 16. Even at the peak at age sixteen some teenagers report low scores, while at the minimum of the U-shape some report high scores. But more importantly, on average, at age 16 there are fewer low scores and more higher scores while at age 50 there are fewer high scores and more low scores. For example, $2.54 \%$ of those age 16 had scores of 4 or less versus $6.30 \%$ of those age 50 . Analogously, $21 \%$ of those aged sixteen scored 10 versus $11 \%$ of those age 50 (Fig. 2). Figure 3 illustrates that the paths of both the high and low scores shows a midlife crisis. It plots the proportion with a low score (0-2), which shows a 
Table 6 UK Well-being over time, 2011-2021, ONS

\begin{tabular}{|c|c|c|c|c|}
\hline & Life satisfaction & Happiness & Worthwhile & Anxious \\
\hline \multicolumn{5}{|l|}{ 2011-March 2021} \\
\hline April 2011-March 2012 & 7.42 & 7.29 & 7.67 & 3.13 \\
\hline April 2012-March 2013 & 7.46 & 7.30 & 7.70 & 3.03 \\
\hline April 2013-March 2014 & 7.51 & 7.39 & 7.74 & 2.92 \\
\hline April 2014-March 2015 & 7.61 & 7.46 & 7.82 & 2.86 \\
\hline April 2015-March 2016 & 7.65 & 7.48 & 7.84 & 2.87 \\
\hline April 2016-March 2017 & 7.68 & 7.51 & 7.86 & 2.90 \\
\hline April 2017-March 2018 & 7.69 & 7.52 & 7.88 & 2.89 \\
\hline April 2018-March 2019 & 7.71 & 7.56 & 7.89 & 2.87 \\
\hline April 2019-March 2020 & 7.66 & 7.48 & 7.86 & 3.05 \\
\hline \multicolumn{5}{|l|}{ March 2020-March 2021} \\
\hline \multicolumn{5}{|l|}{2020} \\
\hline 20-30 March & 7.2 & 6.4 & 7.4 & 5.2 \\
\hline 27 March-6 April & 7.1 & 6.4 & 7.5 & 5.0 \\
\hline 3-13 April & 6.9 & 6.6 & 7.4 & 4.9 \\
\hline 9-20 April & 7.1 & 6.9 & 7.5 & 4.2 \\
\hline 17-27 April & 6.8 & 6.7 & 7.3 & 4.2 \\
\hline 24 April-3 May & 6.9 & 6.8 & 7.3 & 4.1 \\
\hline 1-10 May & 7.2 & 7.0 & 7.5 & 4.0 \\
\hline 7-17 May1 & 6.9 & 6.8 & 7.3 & 4.1 \\
\hline 14-17 May1 & 6.9 & 7.0 & 7.3 & 4.0 \\
\hline 21-24 May & 7.0 & 6.9 & 7.3 & 4.1 \\
\hline 28-31 May & 7.2 & 7.4 & 7.6 & 3.7 \\
\hline 4-7 June & 7.1 & 7.1 & 7.5 & 3.9 \\
\hline 11-14 June & 6.8 & 6.8 & 7.3 & 3.8 \\
\hline $18-21$ June & 6.9 & 7.0 & 7.4 & 3.7 \\
\hline $25-28$ June & 7.0 & 7.1 & 7.3 & 3.6 \\
\hline $2-5$ July & 6.9 & 7.1 & 7.4 & 4.0 \\
\hline $8-12$ July & 7.0 & 7.1 & 7.3 & 4.0 \\
\hline 15-19 July & 6.9 & 7.1 & 7.3 & 4.0 \\
\hline $22-26$ July & 7.0 & 7.0 & 7.4 & 4.0 \\
\hline 29 July -2 August & 7.1 & 7.2 & 7.5 & 4.0 \\
\hline 5-9 August & 7.0 & 7.2 & 7.4 & 4.0 \\
\hline $12-16$ August & 7.0 & 7.2 & 7.4 & 3.7 \\
\hline $26-30$ August & 7.1 & 7.2 & 7.5 & 4.0 \\
\hline 9-13 Sept & 7.1 & 7.2 & 7.5 & 4.1 \\
\hline $16-20 \mathrm{Sept}$ & 6.9 & 7.0 & 7.3 & 3.9 \\
\hline $24-27$ Sept & 6.8 & 6.9 & 7.4 & 4.0 \\
\hline $30 \mathrm{Sept}-4$ Oct & 6.9 & 6.9 & 7.4 & 4.3 \\
\hline $7-11 \mathrm{Oct}$ & 6.8 & 7.0 & 7.4 & 4.0 \\
\hline $14-18$ Oct & 6.7 & 6.9 & 7.3 & 4.3 \\
\hline $21-25$ Oct & 6.7 & 6.8 & 7.2 & 4.2 \\
\hline 28 Oct- $1 \mathrm{Nov}$ & 6.5 & 6.7 & 7.2 & 4.3 \\
\hline $5-8 \mathrm{Nov}$ & 6.8 & 6.8 & 7.3 & 4.1 \\
\hline
\end{tabular}


Table 6 (continued)

\begin{tabular}{lllll}
\hline & Life satisfaction & Happiness & Worthwhile & Anxious \\
\hline 11-15 Nov & 6.7 & 6.7 & 7.3 & 4.2 \\
18-22 Nov & 6.8 & 6.9 & 7.3 & 4.1 \\
25-29 Nov & 6.8 & 6.8 & 7.3 & 4.2 \\
2-6 Dec & 6.8 & 6.8 & 7.3 & 4.1 \\
10-13 Dec & 6.8 & 6.9 & 7.3 & 4.0 \\
16-20 Dec & 6.7 & 6.7 & 7.3 & 4.2 \\
22 Dec '20-3 Jan '21 & 6.7 & 6.9 & 7.2 & 4.0 \\
2021 & & & & \\
7-10 Jan & 6.4 & 6.5 & 7.0 & 4.6 \\
13-17 Jan & 6.4 & 6.4 & 7.1 & 4.3 \\
20-24 Jan & 6.5 & 6.4 & 7.0 & 4.3 \\
27-31 Jan & 6.4 & 6.4 & 7.1 & 4.3 \\
3-7 Feb & 6.4 & 6.5 & 7.1 & 4.2 \\
10-14 Feb & 6.4 & 6.5 & 7.0 & 4.1 \\
17-21 Feb & 6.4 & 6.6 & 7.0 & 4.0 \\
24-28 Feb & 6.6 & 6.7 & 7.1 & 3.9 \\
3-7 March & 6.8 & 6.8 & 7.2 & 3.9 \\
10-14 March & 6.8 & 6.9 & 7.3 & \\
\hline
\end{tabular}

ONS

peak in midlife. It also plots the proportion with the high score of ten, which reaches a low in midlife.

In the former case as individuals age and happiness falls, a higher proportion are in the lowest four categories and a lower proportion are in the highest category. Thus, focusing on the tails not just the mean also shows a midlife low in wellbeing. The U-shape is even more apparent, without the early hill in the 30's when sensible controls are used. This dismisses the claim that this is all about averages and people at the tails are different; it turns out they are not. Of course, using non-random, non-representative samples of 123 people may find something different, but that is not statistically or econometrically appropriate (Table 6 and 7).

As we did in Table 8 using the Eurobarometers in Table 9 we report the same by regressing life on a set of single year of age dummies using these APS data for the UK for those age under seventy. Sample size is around a third of a million respondents. GKJL2 try to hide the existence of the U-shape by redrawing the life satisfaction data for the UK in their Fig. 1c on a bigger scale to try to make the U-shape go away. This is illustrated in Fig. $4 \mathrm{a}$ and $\mathrm{b}$.

GKJL2 argued that it was appropriate to do this as they could make the U-shape look like a straight line!

"Thus, we examined that graph ... and noticed that BG severely truncated the $y$-axis with a range from 7.0 to 8.5 on an 11-point scale. On that truncated scale, the pattern looks like a $U$. When replotted to represent a larger portion of the distribution that includes the range of likely responses on the ... (0 to 10), the data look more like a straight line." 

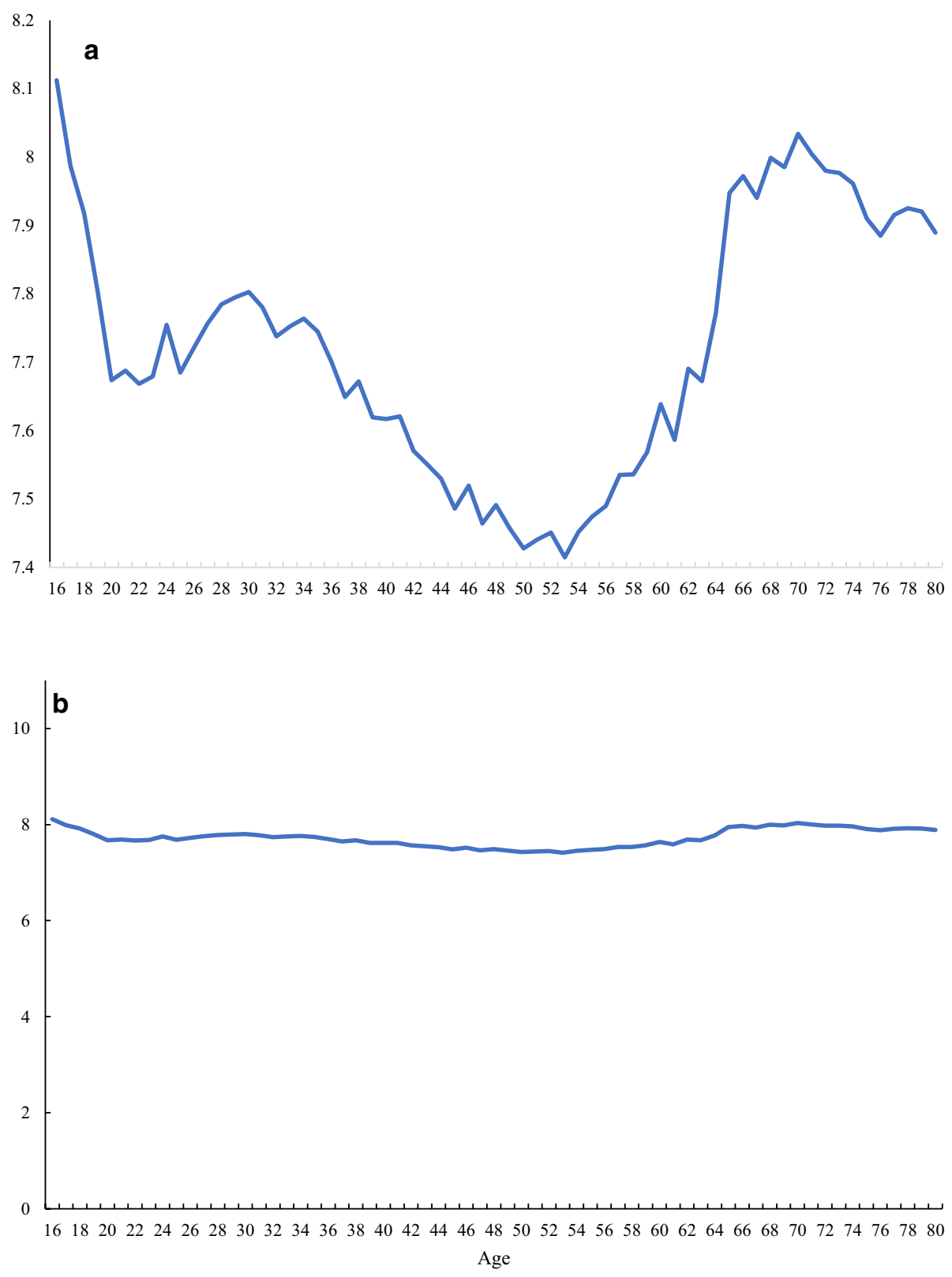

Fig. 4 a Raw Life satisfaction Scores, UK 2016-2019. b Raw Life Satisfaction Scores as Suggested by Galambos et al., 2021a, 2021b

It looks like a $\mathrm{U}$ because it is a U. Changing scales won't hide this reality.

The U-shape is not a straight line as Table 9 shows. It plots the coefficients of the single year of age variables in regressions with and without controls. This is exactly comparable to the official estimates of U-shapes reported by the ONS in Tables 4 and 5. 


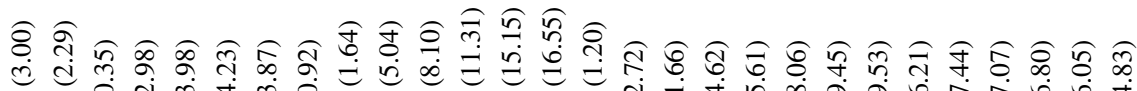

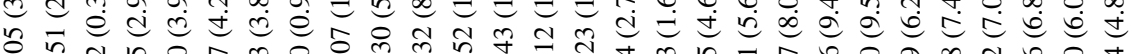

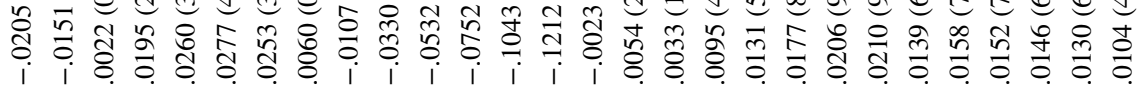

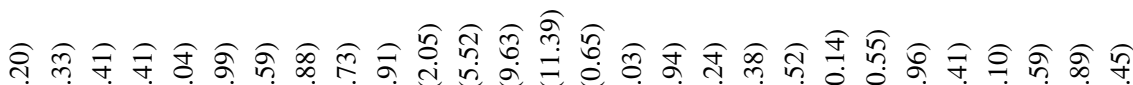
d

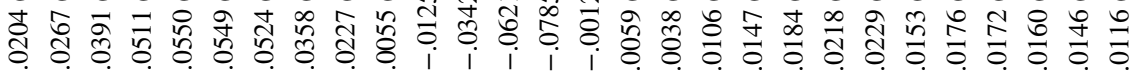

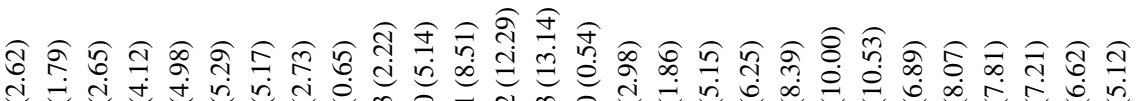

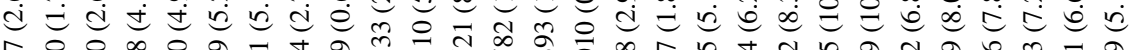

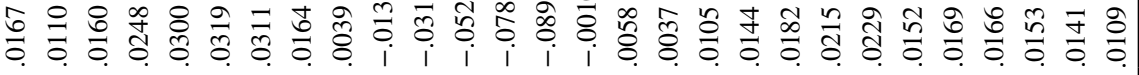




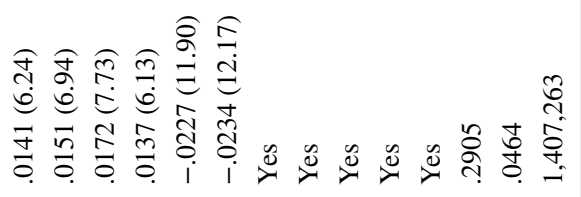

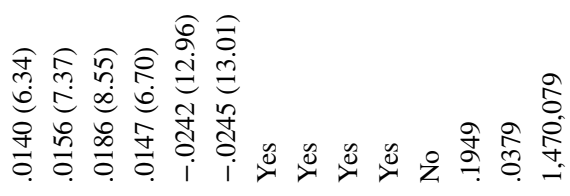

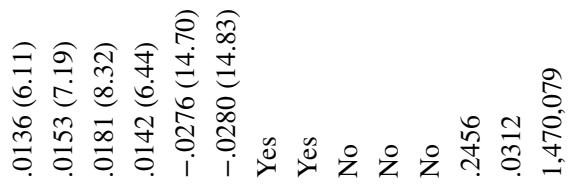

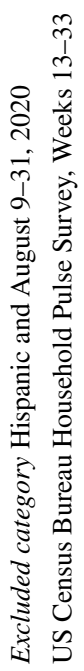

Springer 
The T-statistics are testing whether the individual age coefficient is statistically different from the excluded category, age sixteen which is set to zero. Every single one is, other than age seventeen, with t-statistics greater than two. In the case of age 50, which is the lowpoint of the U-curve, the coefficient of -0.68 observed above has a t-statistic of ten. Given that finding the next question is whether the decline from youth to midlife low is small or large, trivial or substantial. It is large.

\subsection{The Extent of the Drop in Well-Being from Youth to Midlife of 0.67 Life Satisfaction Points is Neither Trivial, Small nor Misleading}

JMTD have claimed that the drop from youth to midlife is trivial. "It is possible that the $U$-shaped (or other) curve exists but that it is so small that it is not practically meaningful...... all changes...stayed within 0.48 of the starting life-satisfaction score at age $20 . . .$. an effect size...so small that it is truly trivial and lacks practical significance. For our Cantril ladder scale, respondents reported (and probably thought) in terms of the nearest whole scale point from 1 to $10 . .$. differences below 1.00 should be considered quite small."

GKJL2 ask "how consequential is a difference between 7.9 and 7.2 on a 10-point scale, particularly when this range illustrates quite high life satisfaction well above the midpoint?" They even go as far as to claim, without any foundation, "generalizing from small age differences...to reach conclusions about a universal crisis in midlife is misleading". It is not clear to us how this claim is misleading given that in addition to our evidence we present here a total of 380 published papers support its existence.

In the APS data, the decline in life satisfaction from being married with spouse present (8.03) to being separated (7.00) on the $0-10$ scale is 1 life satisfaction point. The drop from employed (5.56) to unemployed (4.82) is 0.74 points. The drop from age 16 as we noted above is two thirds of that. The drop from employed (7.79) to unemployed (6.81) is 1.08 life satisfaction points. The answer is highly consequential.

Table 6 presents new data also reported by the ONS that helps us determine whether a fall of 0.67 life satisfaction points is large or not. Part a) of the table reports on how life satisfaction changed from April 2011-March 2022. It rose from 7.42 in the early period to 7.68 in 2016-2017 and then remained steady at around 7.7 through to March 2020. Then COVID and lockdowns hit. The ONS continued to use the same question, this time in its Opinions and Lifestyle Survey. Part b) of the table shows that it fell to a low of 6.4 in early 2021 before picking up to 6.8 in March 2021 as vaccines became available. So, during COVID life satisfaction dropped from 7.7 to 6.4 , a drop of 1.3 life satisfaction points, or double what we observed from youth to midlife. The psychologists who argue the size of the drop is non-consequential have not identified a single life event that has a decline of comparable magnitude.

\section{Bureau of the Census Household Pulse Surveys, Week 24, February 3rd-15th $2021^{18}$}

It is known that there is an inverted U-shape in age in unhappiness (Blanchflower \& Oswald, 2008; Blanchflower, 2020b). This is found for many different countries and multiple unhappiness measures including many not good mental health days; anxiety; worry;

18 www.census.gov/data/tables/2021/demo/hhp/hhp24.html. 
loneliness; sadness; stress; pain; strain, depression and bad nerves; phobias and panic; being downhearted; having restless sleep; losing confidence in oneself; not being able to overcome difficulties; being under strain; being unhappy; feeling a failure; feeling left out; feeling tense; and thinking of yourself as a worthless person. It turns out that the taking anti-depressant medications follow a similar path.

The US Census Bureau has been conducting Household Pulse Surveys since April 24th, 2020, looking at various aspects of well-being since the arrival of COVID. Micro-data are released two weeks after the publication of the main data tables. The variable of particular interest is on the taking anti-depressants. Taking of antidepressants is, by a kind of revealed preference, a potentially informative signal of mental distress, both about the person taking them and, more broadly, potentially about patterns in society at the aggregate level. This follows work by Blanchflower and Oswald (2016), who examined data on taking of anti-depressants in EU countries and found an inverted U-shape. They found that one in thirteen Europeans have taken an antidepressant in the previous twelve months. The rates of anti-depressant use are greatest in Portugal, Lithuania, France and the UK.

Here we examine similar data for the first time in the U.S. on whether an individual took anti-depressants over the last month.

Q7. Over the prior four weeks have you taken prescription medications to help with any emotions or with your concentration, behavior or mental health?"

We have micro data available in twenty-one surveys from week \#13 August $19^{\text {th }}-31$ st through week \#33 June $23^{\text {rd }}$-July $5 \mathrm{th}^{19}$. Overall, the weighted data suggests that is true of $20.8 \%$ of those who answered. The issue is whether the taking of prescription medications also has an inverted U-shape in age; the answer is that it does. Table 7, with a sample size of over 1.4 million, illustrates that this is the case whether controls are included or not. The dependent variable is 1 if the respondent takes prescription medications, zero otherwise. Controls in column 1 race, gender and state plus age and interview data dummies. In column 2 education and marital status dummies are added and income is added in column 3. IN all three specifications taking of anti-depressants peaks in middle age: in columns 1 and 3 in the age range 5-49. In column 2 ages 40-44 and 45-49 are not significantly different from each other. Of note is the probability of taking anti-depressant medications peaks just after the presidential election of November $20^{\text {th }}, 2020$. It has fallen sharply since then and by June 2021 was below its level in August 2020. There is an inverted U-shape in age in anti-depressant taking in the United States.

\section{Discussion}

An early psychology literature argued that there was no relationship between well-being and age. This appears to have been based on studies that included a handful of people with tiny sample sizes. Even where there was evidence of a U-shape, it was denied in the literature. We reworked a few of these studies using same data and showed there were U-shapes, and their scale was large and comparable to the loss of a spouse, or a job. Some studies have failed to find U-shapes but generally they have been based on small sample sizes,

In addition to our findings of U-shapes using life satisfaction data from the Eurobarometer we also looked at Cantril's ladder of life satisfaction in the Gallup World Poll data and

19 This updates work reported in Blanchflower and Bryson (2021). 
found U-shapes with and without controls for an additional 64 non-European countries. We found similar U-shapes for the UK from the Annual Population Surveys.

Two more recent papers (Galambos et al., 2020, 2021) suggested there was little evidence of U-shapes based on a literature review of 28 papers. We showed that the authors had misclassified many of these paper's findings. Indeed, after misclassifications have been accounted for and ineligible studies dropped, $B \& G$ found that there were zero that didn't find any evidence of U-shapes. Of the 28 papers 21 found U-shapes and three had mixed evidence while four had to be excluded as they did not set the criteria set by GKJL1; of note is that GKJL2 did not dispute any of these re-classifications.

We have also identified an astonishing 387 additional papers that the authors had ignored that did find U-shapes, making 403 in total. Indeed, we count a total of 373 published in a vast array of peer-reviewed journals in English, including 73 in this journal alone, that find U-shapes, which was the main criterion the authors set for examination. When this was pointed out to the authors by us in an earlier paper (Blanchflower \& Graham, 2021a) the authors claimed that they did not set out to do an exhaustive review because they "wanted to show support for the view that not all researchers find the U shapes". Hence, their analysis is advocacy not science. There is a U-shape in well-being in midlife.

On the basis of this evidence, it is clearly inappropriate to dismiss the literature on the U-curve as "overblown" or the scale of the effects as trifling, inconsequential or even "trivial". We have shown that the effects of the mid-life dip are comparable to major life events like losing a spouse or a job. We show that the drop from teenage years to the midlife low is about half the size of the unprecedented drop in life satisfaction that occurred during the COVID19 pandemic.

Beyond being empirically interesting, there are implications for substantial parts of the world's population. These dips in well-being are associated with higher levels of depression, including chronic depression, difficulty sleeping, and even suicide. In the U.S., deaths of despair are most likely to occur in the middle-aged years, and the patterns are robustly associated with unhappiness and stress. Across countries chronic depression and suicide rates peak in midlife. The mid-life dip in well-being is robust to within person analysis, also exists with the prescribing of anti-depressants and it extends beyond humans. The evidence comes from both longitudinal and cross-section data, which complement one another, as noted in a recent report by The Lancet's COVID-19 Commission Mental Health Task Force. It remains puzzling then why some psychologists continue to suggest that well-being is unrelated to age.

Based on the significant evidence we present, the decline in mid-life well-being seems real and consequential and has robust linkages to other serious markers of ill-being. The mid-life dip is real, it applies to most of the world's population, excepting countries in which it is very difficult to age — such as those with very high levels of absolute poverty and conflict and low levels of life expectancy. It links to behaviors and outcomes that merit the attention of scholars and policymakers alike. These include rising rates of despair and reported pain among the middle-aged in many rich countries and associated premature mortality due to despair-related deaths, and some similar if less well documented patterns in developing economies. Among other things, more public awareness of how common this mid-life dip is might help those navigating its worst manifestations to make it through to a happier and longer life.

The overwhelming evidence from four hundred and nine papers, and counting, as well as the evidence presented here, support the conclusion that there is a midlife low in wellbeing. This is among the most striking, persistent and consistent patterns in social science. 


\section{Appendix}

See Tables 8 and 9.

Table 8 Estimated Age Effects from Life Satisfaction equations, Europe, 2009-2019

\begin{tabular}{|c|c|c|c|}
\hline Age & (1) & (2) & (3) \\
\hline 15 & & & 3.32 \\
\hline 16 & $-.0455(4.04)$ & $-.0388(3.55)$ & 3.26 \\
\hline 17 & $-.0827(7.57)$ & $-.0665(6.27)$ & 3.22 \\
\hline 18 & $-.1415(13.59)$ & $-.0985(9.74)$ & 3.13 \\
\hline 19 & $-.1764(16.97)$ & $-.1060(10.46)$ & 3.10 \\
\hline 20 & $-.2058(19.94)$ & $-.1273(12.61)$ & 3.06 \\
\hline 21 & $-.2219(21.47)$ & $-.1457(14.37)$ & 3.04 \\
\hline 22 & $-.2370(23.11)$ & $-.1598(15.83)$ & 3.02 \\
\hline 23 & $-.2616(25.55)$ & $-.1814(17.87)$ & 3.00 \\
\hline 24 & $-.2784(27.20)$ & $-.2006(19.63)$ & 3.00 \\
\hline 25 & $-.2802(27.70)$ & $-.2066(20.28)$ & 2.98 \\
\hline 26 & $-.2920(28.65)$ & $-.2210(21.43)$ & 2.99 \\
\hline 27 & $-.3002(29.54)$ & $-.2387(23.13)$ & 2.98 \\
\hline 28 & $-.2979(29.68)$ & $-.2427(23.72)$ & 2.98 \\
\hline 29 & $-.3026(30.07)$ & $-.2519(24.52)$ & 2.99 \\
\hline 30 & $-.3081(31.07)$ & $-.2670(26.30)$ & 2.97 \\
\hline 31 & $-.3063(30.17)$ & $-.2683(25.85)$ & 2.99 \\
\hline 32 & $-.3211(32.36)$ & $-.2897(28.47)$ & 2.97 \\
\hline 33 & $-.3183(31.89)$ & $-.2879(28.12)$ & 2.98 \\
\hline 34 & $-.3248(32.40)$ & $-.2972(28.92)$ & 2.99 \\
\hline 35 & $-.3208(32.68)$ & $-.2963(29.36)$ & 2.96 \\
\hline 36 & $-.3311(33.46)$ & $-.3093(30.42)$ & 2.96 \\
\hline 37 & $-.3510(35.21)$ & $-.3241(31.66)$ & 2.94 \\
\hline 38 & $-.3454(35.29)$ & $-.3208(31.85)$ & 2.94 \\
\hline 39 & $-.355(36.02)$ & $-.3284(32.33)$ & 2.95 \\
\hline 40 & $-.3592(36.80)$ & $-.3333(33.15)$ & 2.93 \\
\hline 41 & $-.3645(36.42)$ & $-.3343(32.51)$ & 2.95 \\
\hline 42 & $-.3789(38.81)$ & $-.3508(34.87)$ & 2.91 \\
\hline 43 & $-.3865(39.00)$ & $-.3541(34.74)$ & 2.92 \\
\hline 44 & $-.4114(41.35)$ & $-.3748(36.63)$ & 2.90 \\
\hline 45 & $-.4033(41.39)$ & $-.3667(36.52)$ & 2.88 \\
\hline 46 & $-.4155(41.92)$ & $-.3716(36.44)$ & 2.90 \\
\hline 47 & $-.4300(43.57)$ & $-.3809(37.50)$ & 2.88 \\
\hline 48 & $-.4350(44.48)$ & $-.3877(38.47)$ & 2.87 \\
\hline 49 & $-.4438(45.02)$ & $-.3890(38.32)$ & 2.87 \\
\hline 50 & $-.4406(45.33)$ & $-.3836(38.27)$ & 2.85 \\
\hline 51 & $-.4484(44.89)$ & $-.3867(37.65)$ & 2.88 \\
\hline 52 & $-.4542(46.54)$ & $-.3898(38.74)$ & 2.86 \\
\hline 53 & $-.4586(46.47)$ & $-.3858(37.97)$ & 2.86 \\
\hline 54 & $-.4780(48.57)$ & $-.4004(39.49)$ & 2.84 \\
\hline 55 & $-.4646(47.64)$ & $-.3868(38.45)$ & 2.85 \\
\hline 56 & $-.4705(47.85)$ & $-.3853(38.01)$ & 2.86 \\
\hline 57 & $-.4728(47.85)$ & $-.3814(37.46)$ & 2.86 \\
\hline
\end{tabular}


Table 8 (continued)

\begin{tabular}{llll}
\hline Age & $(1)$ & $(2)$ & $(3)$ \\
\hline 58 & $-.4917(50.46)$ & $-.3950(39.27)$ & 2.83 \\
59 & $-.4723(48.24)$ & $-.3666(36.26)$ & 2.86 \\
60 & $-.4503(46.59)$ & $-.3335(33.30)$ & 2.87 \\
61 & $-.4481(45.17)$ & $-.3236(31.54)$ & 2.91 \\
62 & $-.4420(45.42)$ & $-.3097(30.63)$ & 2.91 \\
63 & $-.4248(43.47)$ & $-.2836(27.86)$ & 2.93 \\
64 & $-.4179(42.70)$ & $-.2703(26.47)$ & 2.94 \\
65 & $-.4167(43.22)$ & $-.2624(25.94)$ & 2.93 \\
66 & $-.4059(41.30)$ & $-.2456(23.82)$ & 2.98 \\
67 & $-.4137(42.22)$ & $-.2442(23.72)$ & 2.97 \\
68 & $-.4195(42.95)$ & $-.2442(23.78)$ & 2.96 \\
69 & $-.4153(42.11)$ & $-.2354(22.71)$ & 2.98 \\
Cons & 3.2654 & 3.2252 & \\
Adjusted $\mathrm{R}^{2}$ & .2083 & .2559 & \\
$\mathrm{~N}$ & $1,072,597$ & $1,071,978$ & \\
\hline
\end{tabular}

Eurobarometers, 2009-2019. Excluded category age 15. Controls in column 1 country and year. Column 2 adds controls for gender, education, marital and labor force status. Column 3 is unweighted mean life satisfaction score. Countries are Albania; Austria; Belgium; Bulgaria; Croatia; Cyprus; Czech Republic; Denmark; Estonia; Finland; France; Germany; Greece; Hungary; Iceland; Ireland; Italy; Latvia; Lithuania; Luxembourg; Makedonia; Malta; Montenegro; Netherlands; Poland; Portugal; Romania; Serbia; Slovakia; Slovenia; Spain; Sweden; Turkey; Turkish Cyprus and the UK

Table 9 Estimated Age Effects from Life Satisfaction Equations, UK

\begin{tabular}{llll}
\hline Age & $(1)$ & $(2)$ & $(3)$ \\
\hline 16 & & & 8.11 \\
17 & $-.1248(1.49)$ & $-.27607(3.43)$ & 7.98 \\
18 & $-.1925(2.43)$ & $-.42756(5.59)$ & 7.91 \\
19 & $-.3087(4.06)$ & $-.57325(7.80)$ & 7.80 \\
20 & $-.4356(5.87)$ & $-.71130(9.91)$ & 7.67 \\
21 & $-.4204(5.77)$ & $-.75156(10.66)$ & 7.68 \\
22 & $-.4400(6.05)$ & $-.83246(11.83)$ & 7.66 \\
23 & $-.4270(5.93)$ & $-.90299(12.97)$ & 7.67 \\
24 & $-.3527(4.96)$ & $-.86971(12.64)$ & 7.75 \\
25 & $-.4184(5.93)$ & $-.98016(14.35)$ & 7.68 \\
26 & $-.3859(5.52)$ & $-.98063(14.50)$ & 7.72 \\
27 & $-.3482(5.01)$ & $-.98468(14.63)$ & 7.75 \\
28 & $-.3211(4.64)$ & $-1.0016(14.94)$ & 7.78 \\
29 & $-.3116(4.53)$ & $-1.0280(15.41)$ & 7.79 \\
30 & $-.3026(4.41)$ & $-1.0476(15.74)$ & 7.80 \\
31 & $-.3251(4.75)$ & $-1.1127(16.77)$ & 7.78 \\
32 & $-.3689(5.39)$ & $-1.1689(17.63)$ & 7.73 \\
33 & $-.3540(5.19)$ & $-1.1782(17.80)$ & 7.75 \\
34 & $-.3434(5.03)$ & $-1.1869(17.92)$ & 7.76 \\
35 & $-.3632(5.33)$ & $-1.2241(18.52)$ & 7.74 \\
36 & $-.4056(5.96)$ & $-1.2675(19.19)$ & 7.70 \\
\hline & & &
\end{tabular}


Table 9 (continued)

\begin{tabular}{|c|c|c|c|}
\hline Age & (1) & (2) & (3) \\
\hline 37 & $-.4581(6.74)$ & $-1.3213(20.01)$ & 7.64 \\
\hline 38 & $-.4350(6.39)$ & $-1.3216(20.00)$ & 7.67 \\
\hline 39 & $-.4887(7.17)$ & $-1.3776(20.81)$ & 7.61 \\
\hline 40 & $-.493737 .23)$ & $-1.3788(20.80)$ & 7.61 \\
\hline 41 & $-.4896(7.17)$ & $-1.3805(20.83)$ & 7.62 \\
\hline 42 & $-.5404(7.93)$ & $-1.4285(21.58)$ & 7.57 \\
\hline 43 & $-.5602(8.22)$ & $-1.4376(21.71)$ & 7.55 \\
\hline 44 & $-.5824(8.55)$ & $-1.4521(21.96)$ & 7.52 \\
\hline 45 & $-.6252(9.21)$ & $-1.4923(22.64)$ & 7.48 \\
\hline 46 & $-.5923(8.73)$ & $-1.4692(22.29)$ & 7.51 \\
\hline 47 & $-.6482(9.57)$ & $-1.5075(22.92)$ & 7.46 \\
\hline 48 & $-.6212(9.18)$ & $-1.4725(22.41)$ & 7.49 \\
\hline 49 & $-.6544(9.67)$ & $-1.5116(23.00)$ & 7.45 \\
\hline 50 & $-.6843(10.13)$ & $-1.5346(23.39)$ & 7.42 \\
\hline 51 & $-.6716(9.95)$ & $-1.5068(22.98)$ & 7.44 \\
\hline 52 & $-.6611(9.80)$ & $-1.4912(22.76)$ & 7.45 \\
\hline 53 & $-.6980(10.35)$ & $-1.5277(23.32)$ & 7.41 \\
\hline 54 & $-.6604(9.79)$ & $-1.4839(22.64)$ & 7.45 \\
\hline 55 & $-.6383(9.47)$ & $-1.4486(22.12)$ & 7.47 \\
\hline 56 & $-.6240(9.26)$ & $-1.4208(21.70)$ & 7.48 \\
\hline 57 & $-.5772(8.56)$ & $-1.3677(20.87)$ & 7.53 \\
\hline 58 & $-.5781(8.57)$ & $-1.3457(20.53)$ & 7.53 \\
\hline 59 & $-.5457(8.09)$ & $-1.2871(19.63)$ & 7.56 \\
\hline 60 & $-.4759(7.05)$ & $-1.1903(18.16)$ & 7.63 \\
\hline 61 & $-.5282(7.82)$ & $-1.2122(18.48)$ & 7.58 \\
\hline 62 & $-.4237(6.28)$ & $-1.0782(16.44)$ & 7.69 \\
\hline 63 & $-.4423(6.55)$ & $-1.0640(16.23)$ & 7.67 \\
\hline 64 & $-.3440(5.10)$ & $-.9408(14.35)$ & 7.77 \\
\hline 65 & $-.1683(2.50)$ & $-.6937(10.58)$ & 7.94 \\
\hline 66 & $-.1412(2.10)$ & $-.6285(9.59)$ & 7.97 \\
\hline 67 & $-.1748(2.60)$ & $-.6399(9.77)$ & 7.94 \\
\hline 68 & $-.1170(1.74)$ & $-.5539(8.47)$ & 7.99 \\
\hline 69 & $-.1308(1.95)$ & $-.5484(8.40)$ & 7.98 \\
\hline cons & 8.0103 & 8.8015 & \\
\hline Adjusted $\mathrm{R}^{2}$ & .0103 & 0.869 & \\
\hline $\mathrm{N}$ & 327,922 & 327,750 & \\
\hline
\end{tabular}

Annual Population Survey UK, 2016-2019. Excluded category age 15. Controls in column 1 country and year. Column 2 adds controls for gender, education, marital and labor force status. Column 3 is unweighted mean life satisfaction score

\section{Appendix A. 409 Papers Finding U-Shapes in Age in Well-Being as of $10 \mathrm{pm}$ JULY 22nd, 2021}

\section{Papers from Galambos \#1 Finding U-Shapes}

1). Baetschmann, G. (2013), Heterogeneity in the relationship between happiness and age: Evidence from the German Socio-Economic Panel. German Economic Review, 15, 
393-410.

2). Bauer, J. M, Levin, V, Boudet, A. M. M, Nie, P, \& Sousa-Poza, A. (2017), Subjective well-being across the lifespan in Europe and Central Asia. Journal of Population Ageing, 10, 125-158.

3). Beja, E. L, Jr. (2018), The U-shaped relationship between happiness and age: Evidence using World Values Survey data. Quality and Quantity, 52, 1817-1829.

4). Blanchflower, D. G, \& Oswald, A. J. (2019), Unhappiness and pain in modern America: A review essay, and further evidence, on Carol Graham's happiness for all? Journal of Economic Literature, 57, 385-402.

5). Cheng, T. C, Powdthavee, N, \& Oswald, A. J. (2015) Longitudinal evidence for a midlife nadir in human wellbeing: results from four data sets. The Economic Journal, 127, 126-142.

6). Dolan, P, Kudrna, L, \& Stone, A. (2017), The measure matters: An investigation of evaluative and experience-based measures of wellbeing in time use data, Social Indicators Research, 134, 57-73.

7). Ferrante, F. (2017), Great expectations: The unintended consequences of educational choices, Social Indicators Research, 131, 745-767.

8). Graham, C, \& Pozuelo, J. R. (2017), Happiness, stress, and age: How the U curve varies across people and places. Journal of Population Economics, 30, 225-264.

9). Grover, S, \& Helliwell, J. F. (2019), How's life at home? New evidence on marriage and the set point for happiness. Journal of Happiness Studies, 20, 373-390.

10). Hellevik, O. (2017), The U-shaped age-happiness relationship: Real or methodological artifact? Quality and Quantity, 51, 177-197.

11). Kolosnitsyna, M, Khorkina, N, \& Dorzhiev, H. (2017) Determinants of life satisfaction in older Russians. Ageing International, 42, 354-373.

12). Laaksonen, S. (2018), A research note: Happiness by age is more complex than U-shaped, Journal of Happiness Studies, 19, 471-482.

13). Li, N. (2016), Multidimensionality of longitudinal data: Unlocking the age-happiness puzzle, Social Indicators Research, 128, 305-320.

14). Lin, Y. M. (2016), BMI, perceived health status and happiness: The direct vs. indirect effect of obesity. International Journal of Ecological Economics and Statistics, 37(3.

15). Morgan, J, Robinson, O, \& Thompson, T. (2015), Happiness and age in European adults: The moderating role of gross domestic product per capita. Psychology and Aging, 30, 544-551.

16). Mujcic, R, \& Oswald, A. J. (2018), Is envy harmful to a society's psychological health and wellbeing? A longitudinal study of 18,000 adults, Social Science and Medicine, 198, 103-111.

17). Piper, A. T. (2015), Sliding down the U-shape? A dynamic panel investigation of the age-well-being relationship, focusing on young adults, Social Science and Medicine, 143, 54-61.

18). Ruseski, J. E, Humphreys, B. R, Hallman, K, Wicker, P, \& Breuer, C. (2014), Sport participation and subjective wellbeing: Instrumental variable results from German survey data, Journal of Physical Activity and Health, 11, 396-403.

19). Schwandt, H. (2016), Unmet aspirations as an explanation for the age U-shape in wellbeing, Journal of Economic Behavior and Organization, 122, 75-87.

20). Shankar, A, Rafnsson, S. B, \& Steptoe, A. (2015), Longitudinal associations between social connections and subjective wellbeing in the English Longitudinal Study of Ageing. Psychology and Health, 30, 686-698. 
21). Wunder, C, Wiencierz, A, Schwarze, J, \& Küchenhoff, H. (2013), Well-being over the life span: Semiparametric evidence from British and German longitudinal data, The Review of Economics and Statistics, 95, 154-167.

\section{Peer Reviewed Papers Missed by Galambos \#1 in Peer Reviewed Journals in English 2013-2019}

1). Ahmed Lahsen, A, Piper, A.T. (2019), Property rights and intellectual property protection, GDP growth and individual well-being in Latin America. Latin American Economic Review, 28, 12.

2). Akay, A, A. Constant,-C. Giulietti and-Guzi, M. (2017), 'Ethnic diversity and wellbeing,' Journal of Population Economics, 30: 265-306.

3). Ala-Mantila, S, Heinonen, J, Junnila, S, \& Saarsalmi, P. (2018), Spatial nature of urban well-being. Regional Studies, 52(7), 959-973.

4). Ambrey, C.L, Fleming, C.M. (2014), Life satisfaction in Australia: evidence from ten years of the HILDA Survey, Social Indicators Research, 115, 691-714.

5). Angelini, V. Casi-Luca, L. and Corazzini, L. (2015), Life satisfaction of immigrants: does cultural assimilation matter, Journal of Population Economics, 18, 817-844.

6). Arrosa, M.L, Gandelman, N. (2016), Happiness decomposition: female optimism, Journal of Happiness Studies, 17, 731-756.

7). Artés, J, Salinas-Jiménez, \& M.M. Salinas-Jiménez, J. (2014), Small fish in a big pond or big fish in a small pond? The effects of educational mismatch on subjective wellbeing, Social Indicators Research, 119, 771-789.

8). Asadullah, M. N, Xiao, S, \& Yeoh, E. (2018), Subjective well-being in China, 2005-2010: The role of relative income, gender, and location. China Economic Review, 48, 83-101.

9). Ateca-Amestoy, V, Aguilar, A.C. \& Moro-Egido, A.I, (2014), Social interactions and life satisfaction: evidence from Latin America, Journal of Happiness Studies, 15, 527-554.

10). Bai, C, Y.Gong and C. Feng (2019), Social trust, pattern of difference, and subjective well-being, SAGE Open Volume: 9 issue: 3, First Published July 23, 2019.

11). Bartolini, S, Bilancini, E, Sarracino, F. (2013), 'Predicting the trend of well-being in Germany: how much do comparisons, adaptation and sociability matter?' Social Indicators Research, 114:169-191.

12). Başlevent, C, Kirmanoğlu, H. (2014), The impact of deviations from desired hours of work on the life satisfaction of employees, Social Indicators Research, 118, 33-43.

13). Başlevent, C, Kirmanoğlu, H. (2017), Gender inequality in Europe and the life satisfaction of working and non-working women, Journal of Happiness Studies, 18, 107-124.

14). Bauer, J.M, Levin, V, Munoz Boudet, A.M. et al. (2017), Subjective well-being across the lifespan in Europe and Central Asia. Population Ageing, 10, 125-158.

15). Bell, D.N. F and Blanchflower, D.G. (2019), The well-being of the overemployed and the underemployed and the rise in depression in the UK, Journal of Economic Behavior and Organization, 161: 180-196.

16). Bhuiyan, M.F. (2018), Life satisfaction and economic position relative to neighbors: perceptions versus reality, Journal of Happiness Studies, 19, 1935-1964.

17). Bhuiyan M.F. \& R.S. Szulgab (2017), Extreme bounds of subjective well-being: economic development and micro determinants of life satisfaction. Applied Economics, 49(14):1351-1378. 
18). Binder, M, Coad, A. (2016), How satisfied are the self-employed? A life domain view, Journal of Happiness Studies, 17, 1409-1433.

19). Birdal, M, Acun, S. and Onuk, P. (2018), What makes us happy? Socioeconomic determinants of subjective well-being in Turkey, The International Journal of Interdisciplinary Social and Community Studies, 13(4),

20). Blanchflower, D.G. and Oswald, A.J. (2016), Antidepressants and age: a new form of evidence for U-shaped well-being through life, Journal of Economic Behavior and Organization, 127, 46-58.

21). Blanchflower, D.G, Oswald, A.J, and Stewart-Brown, S. (2013), Is psychological wellbeing linked to the consumption of fruit and vegetables? Social Indicators Research, 114(3), 785-801.

22). Bonikowska, A, Helliwell, J, Hou, F. \& Schellenberg, G. (2014), An assessment of life satisfaction responses on recent Statistics Canada Surveys, Social Indicators Research, 118: 617-643.

23). Boyce, C.J, Delaney, L. \& Wood, A.M. (2018), The Great Recession and subjective wellbeing: How did the life satisfaction of people living in the United Kingdom change following the financial crisis? PlosOne, Aug 29th.

24). Brenig, M, Proeger, T. (2018), Putting a price tag on security: subjective well-being and willingness-to-pay for crime reduction in Europe, Journal of Happiness Studies, 19, $145-166$.

25). Brockmann, H, Koch, AM, Diederich, A. et al. Why managerial women are less happy than managerial men, Journal of Happiness Studies, 19, 755-779 (2018),

26). Buddelmeyer, H, \& Powdthavee, N. (2016), Can having internal locus of control insure against negative shocks? Psychological evidence from panel data, Journal of Economic Behavior and Organization, 122, 88-109.

27). Caner, A. (2014), Happiness, comparison effects, and expectations in Turkey, Journal of Happiness Studies, 16, 1323-1345.

28). Cannas, M, Sergi, B. S, Sironi, E, \& Mentel, U. (2019), Job satisfaction and subjective well-being in Europe. Economics and Sociology, 12(4), 183-196.

29). Chang, W. (2013), Climbing up the social ladders: identity, relative income, and subjective well-being, Social Indicators Research, 113: 513-535.

30). Chapman, B, Guven, C. (2016), Revisiting the relationship between marriage and wellbeing: does marriage quality Matter? Journal of Happiness Studies, 17, 533-551.

31). Charles, A, Wu, D. \&.Wu, Z. (2019), Economic shocks on subjective wellbeing: reassessing the determinants of life satisfaction after the 2008 financial crisis, Journal of Happiness Studies, 20: 1041-1055.

32). Cheng, Z. (2014), The effects of employee involvement and participation on subjective wellbeing: evidence from urban China, Social Indicators Research, 118, 457-483.

33). Choi, J, Coughlin and D'Ambrosio (2013), Travel time and subjective well-being, Transportation Research Record: Journal of the Transportation Research Board, 2357(1), 100-108.

34). Churchill, S.A. \& Mishra, V. (2017), Trust, social networks and subjective wellbeing in China, Social Indicators Research, 132: 313-339.

35). Clark, A.E. and C. D'Ambrosio (2019), One size fits all? Well-being, measurement and growth, Annals of the Fondazione Luigi Einaudi, Volume LIII, 101-114.

36). Crum, M. and Y. Chen (2015), Self-employment and subjective well-being: a multi-country analysis, International Journal of Entrepreneurship. Volume 19, 5-28.

37). Cuñado, J. \& de Gracia, F.P. (2013), Environment and happiness: new evidence for Spain, Social Indicators Research, 112: 549-567. 
38). Darbonne, A, Uchino, B.N. \& Ong, A.D. (2013), What mediates links between age and well-being? a test of social support and interpersonal conflict as potential interpersonal pathways, Journal of Happiness Studies, 14, 951-963.

39). Daroudi, R, Rashidian, A. Zeraati, H. Oliyaeemanesh, A. and Sari, A.A. (2016), Life and health satisfaction in the adult population of Iran, Epidemiology and Health, 38.

40). Davis, L. and Wu, S. (2014), Social comparisons and life satisfaction across racial and ethnic groups: the effects of status, information and solidarity, Social Indicators Research, 117: 849-869.

41). Deeming, C. (2013), Addressing the social determinants of subjective wellbeing: the latest challenge for social policy, Journal of Social Policy, 42(3), 541-555.

42). del Saz-Salazar, S, Navarrete-Tudela, A, Alcalá-Mellado, J.R. et al. (2019), On the use of life satisfaction data for valuing cultural goods: a first attempt and a comparison with the contingent valuation method, Journal of Happiness Studies, 20: 119-140.

43). Devine, J, Hinks, T. \& Naveed, A. (2019), Happiness in Bangladesh: the role of religion and connectedness, Journal of Happiness Studies, 20, 351-371.

44). Dickerson, A, A.R. Hole and L.A. Munford (2014) The relationship between wellbeing and commuting revisited: Does the choice of methodology matter? Regional Science and Urban Economics, 49, November, pp. 321-329.

45). Diego-Rosell, P, Tortora, R. \& Bird, J. (2018), International determinants of subjective well-being: living in a subjectively material world, Journal of Happiness Studies, 19, 123-143.

46). Dluhosch, B, Horgos, D. and Zimmermann, K.W, (2014), Social choice and social unemployment-income cleavages: new insights from happiness research, Journal of Happiness Studies, 15, 1513-1537.

47). Downward, P, Dawson, P. (2016), Is it pleasure or health from leisure that we benefit from most? An analysis of well-being alternatives and implications for policy, Social Indicators Research, 126, 443-465.

48). Eichhorn, J. (2013), Unemployment needs context: how societal differences between countries moderate the loss in life-satisfaction for the unemployed, Journal of Happiness Studies, 14, 1657-1680.

49). Eren, K.A. \& Aşıc1, A.A. (2017), The determinants of happiness in Turkey: evidence from city-level data, Journal of Happiness Studies, 18, 647-669.

50). Fang, Z. (2017), Panel quantile regressions and the subjective well-being in Urban China: evidence from RUMiC data, Social Indicators Research, 132: 11-24.

51). Fat, L.N, S. Scholes, S. Boniface, J. Mindell and S. Stewart-Brown (2017), Evaluating and establishing national norms for mental wellbeing using the SWEMWBS,: findings from the Health Survey for England, Quality of Life Research, 26:1129-1144.

52). Gandelman, N, Piani, G. (2013), Quality of life satisfaction among workers and non-workers in Uruguay, Social Indicators Research, 111, 97-115.

53). Gao, S. Meng, X. \& Zhang, L. (2014), Fiscal decentralization and life satisfaction: evidence from urban China, Social Indicators Research, 119:1177-1194.

54). Garrido, S, Méndez, I. \& Abellán, JM. (2013), Analysing the simultaneous relationship between life satisfaction and health-related quality of life, Journal of Happiness Studies, 14, 1813-1838.

55). Gokdemir, O, Tahsin, E. (2014), Factors that influence the life satisfaction of women living in the Northern Cyprus, Social Indicators Research, 115, 1071-1085.

56). Gonza, G, Burger, A. (2017), Subjective well-being during the 2008 economic crisis: identification of mediating and moderating factors, Journal of Happiness Studies, 18, 1763-1797. 
57). Graham, C. Zhou, C. \& Zhang, J. (2017), Happiness and health in China: the paradox of progress. World Development, 96: 231-244.

58). Growiec, K, Growiec, J. (2014), Trusting only whom you know, knowing only whom you trust: the joint impact of social capital and trust on happiness in CEE countries, Journal of Happiness Studies, 15, 1015-1040.

59). Gudmundsdottir, D.G. (2013), The impact of economic crisis on happiness, Social Indicators Research, 110: 1083-1101.

60). Guriev, S. and N. Melnikovd (2018), Happiness convergence in transition countries, Journal of Comparative Economics, 46(3), pp. 683-707.

61). Ha, S.E. and Jang, S.J. (2015), National identity, national pride, and happiness: the case of South Korea, Social Indicators Research, 121: 471-482.

62). Ha, S. and Kim, S. (2013), Personality and subjective well-being: evidence from South Korea, Social Indicators Research, 111: 3341-359.

63). Habibov, N, Afandi, E. (2015), Pre, -and post-crisis life-satisfaction and social trust in transitional countries: an initial assessment, Social Indicators Research, 121, 503-524.

64). Hagstrom, P. and Wu, S. (2016), Are pregnant women happier? Racial and ethnic differences in the relationship between pregnancy and life satisfaction in the US, Review of Economics of the Household, 14: 507-527.

65). Harada, H. and E. Sumi (2018), The happiness and relative income hypothesis in contemporary Japan: a study of lifestyle and values, The Senshu Social Well-being Review, No. 5, 63-74.

66). Hawbam, S. R. (2014). Relation of happiness and coping strategies among adolescents and adults. Indian Journal of Positive Psychology, 5(4), 448-450.

67). Helliwell, J.F. and H. Huang (2013), Comparing the happiness effects of real and on-line friends, PlosOne, published: September. https://doi.org/10.1371/journal.pone. 0072754

68). Helliwell, J.F, \& Wang, S. (2014), Weekends and subjective well-being, Social Indicators Research, 116(2): 389-407.

69). Hou, F. (2014), Keep up with the Joneses or keep on as their neighbours: life satisfaction and income in Canadian urban neighbourhoods, Journal of Happiness Studies, 15: 1085-1107.

70). Hsieh, C.R, Liu, S. and Qin, X. (2019), The hidden costs of mental depression: implications on social trust and life satisfaction, The Manchester School, 87(2): 259-296.

71). Hsu, H.-C. (2019), Age differences in work stress, exhaustion, well-being, and related factors from an ecological perspective. Int. J. Environ. Res. Public Health, 16, 50.

72). Huang, J. (2019), Income inequality, distributive justice beliefs, and happiness in China: evidence from a nationwide survey, Social Indicators Research, 142: 83-105.

73). Jabeen, F. and F.A. Kahn (2016), An empirical analysis of an individuals' happiness in Pakistan, PUTAJ - Humanities and Social Sciences, 23(2) December, pp. 181-199.

74). Kapteyn, A. Lee, J. Tassot, C. Vonkova, H. \& Zamarro, G. (2015), Dimensions of subjective wellbeing, Social Indicators Research, 123: 625-660.

75). Karyani, A. K, Matin, B. K, Gebru, A. A, Dizaj, J. Y, \& Rezaei, S. (2019), Life and health satisfaction and their association toward health-related quality of life, body mass index and chronic diseases in Iran, Journal of Education and Health Promotion, 8, 71.

76). Kirmanoğlu, H, Başlevent, C. (2014), Life satisfaction of ethnic minority members: an examination of interactions with immigration, discrimination, and citizenship, Social Indicators Research, 116, 173-184.

77). Krause-Pilatus, A. (2013), Don't worry, be happy? Happiness and reemployment, Journal of Economic Behavior and Organization, 96:1-20. 
78). Kuroki, M. (2013), Crime victimization and subjective well-being: evidence from happiness data, Journal of Happiness Studies, 14, 783-794.

79). Lam, K.J. \& Liu, P. (2014), Socio-economic inequalities in happiness in China and U.S, Social Indicators Research, 116(2), 509-533.

80). Latif, E. (2016), Happiness and comparison income: evidence from Canada, Social Indicators Research, 128: 161-177.

81). Le Bon, O. \& Le Bon, S. (2014), Age distribution curve in psychiatric admissions inversely correlates with life satisfaction, Psychiatry Research, 219(1), 232-234.

82). Lei, X, Shen, Y, Smith, J.P. et al. (2018), Life satisfaction in China and consumption and income inequalities, Review of Economics of the Household, 16, 75-95.

83). Li, L, Shi, L. (2019), Economic growth and subjective well-being: analyzing the formative mechanism of Easterlin Paradox. Journal of Chinese Sociology, 6, 1.

84). Liao, P. (2014), More happy or less unhappy? Comparison of the balanced and unbalanced designs for the response scale of general happiness, Journal of Happiness Studies, 15: 1407-1423.

85). Liao, Ps, Shaw, D. \& Lin, Y. (2015), Environmental quality and life satisfaction: subjective versus objective measures of air quality, Social Indicators Research, 124, 599-616.

86). Lingli, X, F.Min and W. Liang (2018), A dynamic analysis on the impact of main life domains satisfaction on happiness, Journal of Finance and Economics, Vol. 44, Issue 12 , pp. $57-69$.

87). Linley, P.A, Dovey, H, Beaumont, S. et al. (2016), Examining the intensity and frequency of experience of discrete positive emotions, Journal of Happiness Studies, 17, 875-892.

88). Macchia, L. and Plagnol, A. C. (2019), Life satisfaction and confidence in national institutions: evidence from South America, Applied Research in Quality of Life, 14: 721-736.

89). Manning, M, Fleming, C.M. and Ambrey, C.L. (2016), Life satisfaction and individual willingness to pay for crime reduction, Regional Studies, 50(12): 2024-2039.

90). Markussen, T, Fibæk, M, Tarp, F. and Tuan, N.D.A. (2018), The happy farmer: self-employment and subjective well-being in rural Vietnam, Journal of Happiness Studies, 19, 1613-1636.

91). Massina, S. and Koppa, P. (2014), 'Is life satisfaction hump-shaped with alcohol consumption? Evidence from Russian panel data, Addictive Behaviors, 39(4), 803-810.

92). Mertens, A, Beblo, M. (2016), Self-reported satisfaction and the economic crisis of 2007-2010: Or How people in the UK and Germany perceive a severe cyclical downturn, Social Indicators Research, 125, 537-565.

93). Mishra, V, Nielsen, I. \& Smyth, R. (2014), How does relative income and variations in short-run wellbeing affect wellbeing in the long run? empirical evidence from China's Korean Minority, Social Indicators Research, 115, 67-91.

94). Morgan, R. and Wang, F. (2019), Wellbeing in transition; life satisfaction in urban China from 2002-2012, Journal of Happiness Studies, 20(8): 2609-2629.

95). Morrison, P.S, A.M. Snider, (2013), The generation gap: age and well-being in New Zealand, New Zealand Population Review.

96). Moschion, J, \& Powdthavee, N. (2018), The welfare implications of addictive substances: A longitudinal study of life satisfaction of drug users, Journal of Economic Behavior \& Organization, 146, 206-221.

97). Mouratidis, K. (2019), Compact city, urban sprawl, and subjective well-being. Cities, 92, September: 261-272. 
98). Mujcic, R. \& Oswald, A.J. (2018), Is envy harmful to a society's psychological health and wellbeing? A longitudinal study of 18,000 adults, Social Science and Medicine, 198: 103-111.

99). Navarro, M, Salverda, W. (2019), Earner position and job and life satisfaction: do contributions to the household income have the same effect by gender and occupations? Journal of Happiness Studies, 20, 2227-2250.

100). Neira, I, Bruna, F, Portela, M. et al. (2018), Individual well-being, geographical heterogeneity and social capital, Journal of Happiness Studies, 19, 1067-1090.

101). Ngoo, Y.T, Tey, N.P. \& Ta, E.C. (2015), Determinants of life satisfaction in Asia, Social Indicators Research, 124: 141-156.

102). Neira, I, Bruna, F, Portela, M. et al. (2018), Individual well-being, geographical heterogeneity and social capital, Journal of Happiness Studies, 19, 1067-1090.

103). Neira, I, Lacalle-Calderon, M, Portela, M, \& Perez-Trujillo, M. (2018), Social capital dimensions and subjective well-being: A quantile approach, Journal of Happiness Studies, 20, 2551-2579.

104). Nowok, B, van Ham, M, Findlay, A.M, Gayle, V. (2013), Does migration make you happy? A longitudinal study of internal migration and subjective well-being, Environment and Planning, 45: 986-1002.

105). Obućina, O. (2013), The patterns of satisfaction among immigrants in Germany, Social Indicators Research, 113: 1105-1127.

106). Okulicz-kozaryn, A, \& Mazelis, J. M. (2017), More unequal in income, more unequal in wellbeing, Social Indicators Research, 132(3), 953-975.

107). Olgiati, A, Calvo, R. \& Berkman, L. (2013), Are migrants going up a blind alley? Economic migration and life satisfaction around the world: cross-national evidence from Europe, North America and Australia, Social Indicators Research, 114, 383-404.

108). Osberghaus, D. and J. Kühling (2016), Direct and indirect effects of weather experiences on life satisfaction - which role for climate change expectations? Journal of Environmental Planning and Management, 59(12), pp. 2198-2230.

109). Oshio, T. (2017), Which is more relevant for perceived happiness, individual-level or area-level social capital? A multilevel mediation analysis, Journal of Happiness Studies, 18, 765-783.

110). Pagán-Rodríguez, R. Disability, training and job satisfaction, Social Indicators Research, 122, 865-885 (2015),

111). Paparusso, A. (2018), Studying immigrant integration through self-reported life satisfaction in the country of residence. Applied Research in Quality Life.

112). Perales, F. (2016), The costs of being "different": sexual identity and subjective wellbeing over the life course, Social Indicators Research, 127, 827-849.

113). Pereira, M.C, Coelho, F. (2013), Untangling the relationship between income and subjective well-being: the role of perceived income adequacy and borrowing constraints, Journal of Happiness Studies, 14, 985-1005.

114). Piper, A. (2016), Sleep duration and life satisfaction. International Review of Economics, 63: 305-325.

115). Piper, A.T. (2015), Europe's Capital cities and the happiness penalty: an investigation using the European Social Survey, Social Indicators Research, 123, 103-126.

116). Piper, A. (2015), Sliding down the U-shape? A dynamic panel investigation of the age-well-being relationship, focusing on young adults, Social Science and Medicine, 143, pp. 54-61. 
117). Powdthavee, N, Burkhauser, R. V, \& De Neve, J. E. (2017), Top incomes and human well-being: evidence from the Gallup World Poll, Journal of Economic Psychology, 62, 246-25.

118). Rahayu, T.P. \& Harmadi, S.H.B. (2016), The effect of income, health, education, and social capital on happiness in Indonesia. Asian Social Science; 12(7), 75-87.

110). Rahayu, T.P. (2016), The determinants of happiness in Indonesia. Mediterranean Journal of Social Sciences, 7(2), March, 393-404.

120). Reeskens, T, Vandecasteele, L. (2017), Economic hardship and well-being: examining the relative role of individual resources and welfare state effort in resilience against economic hardship, Journal of Happiness Studies, 18, 41-62.

121). Rodríguez-Pose, A, von Berlepsch, V, (2014), Social capital and individual happiness in Europe, Journal of Happiness Studies, 15, 357-386.

122). Rözer, J. \& Kraaykamp (2013), Income inequality and subjective well-being: a cross national study on the conditional effects of individual and national characteristics, Social Indicators Research, 113, 1009-1023.

123). Salinas-Jiménez, M.M, Artés, J. \& Salinas-Jiménez, J. (2013), How do educational attainment and occupational and wage-earner statuses affect life satisfaction? A gender perspective study, Journal of Happiness Studies, 14, 367-388.

124). Samuel, R. and Hadjar, A. (2016), How welfare-state regimes shape subjective well-being across Europe, Social Indicators Research, 129: 565-587.

125). Sander, W. (2017), Religion, religiosity, and happiness, Review of Religious Research, 59: 251-262.

126). Sarracino, F. (2013), Determinants of subjective well-being in high- and lowincome countries: Do happiness equations differ across countries, The Journal of SocioEconomics, 42: 51-66.

127). Sarracino, F. (2014), Richer in money, poorer in relationships and unhappy? Time series comparisons of social capital and well-being in Luxembourg, Social Indicators Research, 115: 561-622.

128). Sato, M, J.S. Jordan, D.C. Funk \& M.L. Sachs (2018), Running involvement and life satisfaction: The role of personality, Journal of Leisure Research, Volume 49, Issue 1 pp.28-45.

129). Sekulova, F, \& van den Bergh, J.C.J.M. (2016), Floods and happiness: empirical evidence from Bulgaria. Ecological Economics, 126, 51-57.

130). Shams, K. (2016), Developments in the measurement of subjective well-being and poverty: an economic perspective, Journal of Happiness Studies, 17, 2213-2236.

131). Shams, K, \& Kadow, A. (2018), Happiness across the life span: Evidence from urban Pakistan. FWU Journal of Social Sciences, 12(1), 17-30.

132). Shankar, A, Rafnsson S.B. \& Steptoe, A. (2015), Longitudinal associations between social connections and subjective wellbeing in the English Longitudinal Study of Ageing, Psychology \& Health, 30(6), 686-698.

133). Sherman, A, Shavit, T. (2018), The thrill of creative effort at work: an empirical study on work, creative effort and well-being, Journal of Happiness Studies, 19, 2049-2069.

134). Shishido, K. \& Sasak, T. (2019), Happiness in Japan: A hierarchical age-periodcohort analysis based on JGSS cumulative data 2000-2015. Quality of Life in Japan: $15-45$.

135). Sironi, E. (2019), Job satisfaction as a determinant of employees' optimal wellbeing in an instrumental variable approach. Quality \& Quantity, (2019), 53:1721-1742. 
136). Smith, J.P. Lei, X, Shen, Y. and Zhou, G. (2018), Fertility, gender preference, the Birth Planning Policy and life satisfaction in China, Journal of Population Research, 35: $23-40$.

137). Sohn, K. (2016), The role of spousal income in the wife's happiness, Social Indicators Research, 126, 1007-1024.

138). Sohn, K. (2016), Height and happiness in a developing country, Journal of Happiness Studies, 17, 1-23.

139). Song, Y, A. Zhou, M. Zhang and H. Wang (2019), Assessing the effects of haze pollution on subjective well-being based on Chinese General Social Survey, Journal of Cleaner Production, 235, pp. 574-582,

140). Sørensen, J. Rural-urban differences in life satisfaction: evidence from the European union, Regional Studies, 18(9), pp. 1451-1466.

141). Steele, L.G, Lynch, S.M. (2013), The pursuit of happiness in China: individualism, collectivism, and subjective well-being during China's economic and social transformation, Social Indicators Research, 114, 441-451.

142). Stone, A.A, Schneider, J. and Broderick, J.E. (2017), Psychological stress declines rapidly from age 50 in the United States: yet another well-being paradox, Journal of Psychosomatic Research, 103: 22-28.

143). Sujarwoto, S, Tampubolon, G. and Pierewan, A.C. (2018), Individual and contextual factors of happiness and life satisfaction in a low middle-income country, Applied Research in Quality of Life, 13, 927-945.

144). Sujarwoto, S. (2019), Does happiness pay? A longitudinal Family Life Survey, Applied Research in Quality of Life.

145). Sulemana, I. (2015), An empirical investigation of the relationship between social capital and subjective well-being in Ghana, Journal of Happiness Studies, 16, 1299-1321.

146). Sulemana, I, Doabil, L. \& Anarfo, E.B. (2019), International remittances and subjective wellbeing in Sub-Saharan Africa: a micro-level study, Journal of Family and Economic Issues, 40: 524-539.

147). Sun, S, Chen, J, Johannesson, M, Kind, P, Burström, K. (2016), Subjective wellbeing and its association with subjective health status, age, sex, region, and socio-economic characteristics in a Chinese population study, Journal of Happiness Studies, 17(2), 833-873.

148). Tao, HL. (2019), Marriage and happiness: evidence from Taiwan, Journal of Happiness Studies, 20, 1843-1861.

149). Tani, M. (2017), Hukou changes and subjective well-being in China, Social Indicators Research, 132: 47-61.

150). Tiefenbach, T. \& Kohlbacher, F. (2015), Happiness in Japan in times of upheaval: empirical evidence from the National Survey on Lifestyle Preferences, Journal of Happiness Studies, 16, 333-316.

151). Trung, N.N, Cheong, K. Pham, K.C, Nghi, P.T. and Kim, W.J. (2013), Relationship between socioeconomic values and wellbeing: an overview research in Asia, Social Indicators Research, 111: 451-472.

152). Tsurumi, T, Managi, S. (2017), Monetary valuations of life conditions in a consistent framework: the life satisfaction approach, Journal of Happiness Studies, 18, 1275-1303.

153). Tumen, S. \& Zeydanli, T. (2014), Day-of-the-week effects in subjective wellbeing: does selectivity matter? Social Indicators Research, 119: 139-162.

154). Van Ootegem, L, Verhofstadt, E. (2015), Perceived capabilities as an aggregated indicator for well-being. Applied Research in Quality Life, 10, 615-629. 
155). Vang, Z.M, Hou, F. \& Elder, K. (2019), Perceived religious discrimination, religiosity, and life satisfaction, Journal of Happiness Studies, 20, 1913-1932.

156). Venetoklis, T. (2019), Do interactions cancel associations of subjective well-being with individual-level socioeconomic characteristics? An exploratory analysis using the European Social Survey. Quality \& Quantity, 53, 3033-3061.

157). Wang, M, Wong, M.C.S. (2014), Happiness and leisure across countries: evidence from international survey data, Journal of Happiness Studies, 15, 85-118.

158). Western, M. and Tomaszewski, W. (2016), Subjective wellbeing, objective wellbeing and inequality in Australia, PlosOne, October.

159). Wheatley, D. and Bickerton, C. (2017), Subjective well-being and engagement in arts, culture and sport, Journal of Cultural Economics, 1:23-45.

160). Wheatley, D. and S.L. Buglass (2019), Social network engagement and subjective well-being: a life-course perspective, British Journal of Sociology, 70(5), pp.1971-1995.

161). Wu, H.F, Tam, T. (2015), Economic development and socioeconomic inequality of well-being: a cross-sectional time-series analysis of urban China, 2003-2011, Social Indicators Research, 124, 401-425.

162). Xing, Z, Huang, L. (2014), The relationship between age and subjective wellbeing: evidence from five capital cities in mainland China, Social Indicators Research, 117, 743-756.

163). Yamamura, E, Tsutsui, Y, Yamane, C. et al. (2015), Trust and happiness: comparative study before and after the Great East Japan Earthquake, Social Indicators Research, 123, 919-935.

164). Yildirim, J. Kose, T. and Tanrivere, G. (2019), The effects of terrorism on happiness: Evidence from Turkey, The Economics of Peace and Security, 14(2): 5-20.

165). Zhou, D, Peng, L. (2018), The relationship between the gender gap in subjective well-being and leisure activities in China, Journal of Happiness Studies, 19, 2139-2166.

166). Xu, W, H. Sun, B. Zhu, W. Bai, X.Yu, R. Duan, C.Kou and W. Li (2019), Analysis of factors affecting the high subjective well-being of Chinese residents based on the 2014 China Family Panel Study, Int. J. Environ. Res. Public Health, 16(14), 2566.

167). Zacher, H, Jimmieson, N. L, \& Bordia, P. (2014), Time pressure and coworker support mediate the curvilinear relationship between age and occupational well-being, Journal of Occupational Health Psychology, 19(4), 462-475.

168). Zhou, S, Yu, X. (2017), Regional heterogeneity of life satisfaction in urban China: evidence from hierarchical ordered logit analysis, Social Indicators Research, 132, 25-45.

\section{Peer Reviewed Papers Published Since 2019 in English Fitting Galambos \# 1 Criteria}

1). Abokyi, E, Strijker, D, Asiedu, K.F. et al. (2021), Buffer stock operations and wellbeing: the case of smallholder farmers in Ghana, Journal of Happiness Studies.

2). Ahn, Y.-J. (2021), Do informal social ties and local festival participation relate to subjective well-being? International Journal of Environmental Research in Public Health, 18, 16.

3). Akaeda, N. (2020), Contextual social trust and well-being inequality: from the perspectives of education and income, Journal of Happiness Studies, 21:2957-2979.

4). Albiol-Sánchez, J, Diaz-Serrano, L. \& Teruel, M. (2020), The transition to selfemployment and perceived skill-mismatches: panel data evidence from eleven EU Countries, Social Indicators Research, 153, 957-977. 
5). Amini, C, Douarin, E. (2020), Corruption and life satisfaction in transition: is corruption a social norm in Eastern Europe? Social Indicators Research, 151, 723-766.

6). Arrondo, R, Cárcaba, A. \& González, E. (2020), Drivers of subjective well-being in Spain: are there gender differences? Applied Research in Quality of Life.

7). Bartram, D. (2021), Cross-sectional model-building for research on subjective wellbeing: gaining clarity on control variables, Social Indicators Research.

8). Bell, D. and D.G. Blanchflower (2021), The U-shape of happiness in Scotland, Scottish Journal of Political Economy, first published 17 May 2021.

9). Bittmann, F. (2020), Beyond the U-Shape: mapping the functional form between age and life satisfaction for 81 countries utilizing a cluster procedure, Journal of Happiness Studies, 22: 2343-2359.

10). Blanchflower, D.G. (2021), 'Is happiness U-shaped? Age and subjective wellbeing in 145 countries, Journal of Population Economics, 34(2), pp. 575-624.

11). Blanchflower, D.G. (2020a), Unhappiness and age, Journal of Economic Behavior and Organization, 176, 461-488.

12). Blanchflower, D.G. (2020b), Experienced life cycle satisfaction in Europe: a comment. Review of Behavioral Economics, 7(2), 197-200.

13). Blanchflower, D.G. \& Bryson, A. (2021), Unemployment disrupts sleep, Journal of Economics and Human Biology, forthcoming.

14). Blanchflower, D.G. Bryson, A. and C. Green (2020b), 'Now unions increase job satisfaction and well-being,' British Journal of Industrial Relations, forthcoming.

15). Blanchflower, D.G. and A.E. Clark (2021), Children, unhappiness and family finances, Journal of Population Economics, 34(2), pp. 625-653.

16). Blanchflower, D.G. and Graham, C. (2021), The mid-life dip in well-being: a critique, Social Indicators Research, forthcoming.

17). Blanchflower, D.G. \& Graham, C. (2021), 'The U-shape of happiness: a response,' Perspectives on Psychological Science, forthcoming.

18). Blanchflower, D.G. and Oswald, A.J. (2020) Trends in extreme distress in the United States, 1993-2019, American Journal of Public Health, 110, pp. 1538-1544.

19). Boem, J.R. \& A.J. Oswald (2021), The analysis of human feelings: a practical suggestion for a robustness test, Review of Income and Wealth,

20). Boncompte, J.G, Paredes, R.D. (2020), Human capital endowments and gender differences in subjective well-being in Chile, Journal of Happiness Studies, 21, 241-269.

21). Case, A, A. Deaton and A. Stone (2020), 'Decoding the mystery of American pain reveals a warning for the future,' Proceedings of the National Academy of Sciences, October 6, 2020, 117 (40), pp. 24,785-24,789.

22). Castellacci, F, \& Schwabe, H. (2020), Internet, unmet aspirations and the U-shape of life, PlosOne, June 5th.

23). Castellacci, F. \& Clara Viñas-Bardolet (2020), Permanent contracts and job satisfaction in academia: evidence from European countries, Studies in Higher Education, https://doi.org/10.1080/03075079.2019.1711041

24). Cheng, M. (2020) Are people happier with larger green space? A study of greenness and happiness in urban China, Journal of Chinese Economic and Business Studies, 18:2, 183-201, https://doi.org/10.1080/14765284.2020.1798639

25). Chesters, J, Simona, J. \& Suter, C. (2021), Cross-national comparison of age and period effects on levels of subjective well-being in Australia and Switzerland During Volatile Economic Times (2001-2016), Social Indicators Research, 154: 361-391. 
26). Choi, I., J. Kim, E. Choi, J. Choi, H.W. Suk and J. Na (2021) How COVID-19 affected mental well-being: An 11- week trajectories of daily well-being of Koreans amidst COVID-19 by age, gender and region, PlosOne, Published: April 23, 2021.

27). Clark, A.E, H. d'Albis and A. Greulich (2021), The age U-shape in Europe: the protective role of partnership,' Vienna Yearbook of Population Research, 19, pp. 1-26.

28). Daroudi R, Rashidian A, Zeraati H, Oliyaeemanesh A, Akbari Sari A. (2016), Life and health satisfaction in the adult population of Iran. Epidemiology and Health, 38: e2016047.

29). Davis, L, Wu, S. (2020), The taste for status in international comparison, Journal of Happiness Studies, 21, 2237-2256.

30). Debono, N. (2020), The determinants of well-being during a time of economic growth: the case of selected European Union member states, Mediterranean Journal of Social Sciences, 11(4).

31). Ding, J, Salinas-Jiménez, J. \& Salinas-Jiménez, M. (2020), The impact of income inequality on subjective well-being: the case of China, Journal of Happiness Studies.

32). Eichstaedt, J. C, Yaden, D. B, Ribeiro, F, Adler, A, \& Kern, M. L. (2020), Lifestyle and wellbeing: Exploring behavioral and demographic covariates in a large US sample, International Journal of Wellbeing, 10(4), 87-112.

33). FitzRoy, F.R., Nolan, M.A. (2021) Income Status and Life Satisfaction. Journal of Happiness Studies.

34). Gash, V. and A. Piagnol (2020), The partner pay gap - associations between spouses' relative earnings and life satisfaction among couples in the UK, Work, Employment and Society, 35(3), pp. 566-583.

35). Glatz, C. and Ede, A. (2020), Patterns of trust and subjective well-being across Europe: new insights from repeated cross-sectional analyses based on the European Social Survey 2002-2016, Social Indicators Research, 148:417-439.

36). Gondek D, Bann D, Patalay P, Goodman A, McElroy E, Richards M, Ploubidis GB (2020), Psychological distress from early adulthood to early old age: evidence from the 1946, 1958 and 1970 British birth cohorts, Psychological Medicine, 1-10.

37) Gondek, D., B. Moltrecht and G.B. Ploubidi (2021), Mental health crisis in midlife - a proposed research agenda. Research Ideas and Outcome Journal, 8.

38). Graham and S. Pinto (2020), 'The geography of desperation in America: the role of labor force participation, mobility, and place,' Social Science and Medicine, 270, February, 113,612 .

39). Griffith, G.J, K. Jones (2020), When does geography matter most? Age-specific geographical effects in the patterning of, and relationship between, mental wellbeing and mental illness, Health \& Place, 64,102,401.

40). Hand, C. (2020), Spatial influences on domains of life satisfaction in the UK, Regional Studies, Volume 54, 2020-Issue 6: 802-813.

41). Henriques, C.O, Lopez-Agudo, L.A, Marcenaro-Gutierrez, O.D. et al. Reaching compromises in workers' life satisfaction: a multi-objective interval programming approach, Journal of Happiness Studies, (2021), 22, 207-239.

42). Hinks, T. (2020), Fear of robots and life satisfaction, International Journal of Social Robotics, accepted 26 February 2020.

43). Hu, M. Y. Yang and X. Yu (2020), Living better and feeling happier: An investigation into the association between housing quality and happiness, Growth and Change, 51(3), 1224-1238. 
44). Jensen, R.A.A, Thomsen, D.K, O'Connor, M, and Mehlsen, M.Y. (2020), Age differences in life stories and neuroticism mediate age differences in subjective well-being, Population Ageing; 34(3): 3-15.

45). Johnes, G. (2020), Valuing the impact on wellbeing of urban amenities in Beijing, Journal of Chinese Economic and Business Studies, online 10th September 2020.

46). Jongsma, HE, VG Moulton, GB Ploubidis, E. Gilbert, M. Richards and P. Patalay (2020), Psychological distress across adulthood: test-equating in three British birth cohorts, MedRXiv,

47). Kageyama, J, Sato, K. (2021), Explaining the U-shaped life satisfaction: dissatisfaction as a driver of behavior. Journal of Bioeconomics, 90.

48). Kennedy, J. (2020), Subjective wellbeing and the discount rate, Journal of Happiness Studies, 21, 635-658.

49). Knight, J, M. Bianjing and R. Gunatilika (2021), The puzzle of falling happiness despite rising income in rural China: eleven hypotheses, Economic Development and Cultural Change.

50). Kuan, M, Wang, J. Liou, Y. \& Peng, L. (2020), Exploring the association between life perceptions and emotional profiles in Taiwan: empirical evidence from the National Well-Being Indicators Survey. International Journal of Environmental Research \& Public Health, 17(12), 4209.

51). Lee S.Y, R. Kim, J. Rodgers and S.V. Subramanian (2020), Associations between subjective wellbeing and macroeconomic indicators: an assessment of heterogeneity across 60 countries, Wellbeing, Space and Society, first online 24th November 2020.

52). Lee, S.Y, Ohtake, F. (2021), How conscious are you of others? further evidence on relative income and happiness, Journal of Happiness Studies, forthcoming.

53). Lubian, D. (2020), Are virtuous people happier? Evidence from Italy, Economics and Sociology, 13(1), 146-164.

54). Lu, H, Tong, P. \& Zhu, R. (2020), Longitudinal evidence on social trust and happiness in china: causal effects and mechanisms, Journal of Happiness Studies, 21, 1841-1858.

55). Luo, J. (2020), A Pecuniary explanation for the heterogeneous effects of unemployment on happiness, Journal of Happiness Studies, 21, 2603-2628.

56). Lysberg, F, T.B. Bertelsen, C. Lysberg, M.Høie, G.A. Espnes, S.T. Innstrand (2021), Change and stability: Within-person life satisfaction over a 20-year period using data from the HUNT survey, Scandinavian Journal of Public Health, first published online September 20, 2020.

57). Ma, Y. and Di. Chen (2020), 'Openness, rural-urban inequality, and happiness in China,' Economic Systems, 44(4), 100,834.

58). Mavruk, C, Kıral, E. \& Kıral, G. (2021), Spatial effects over time-framed happiness, Journal of Happiness Studies, 22, pp. 517-554.

59). Morgan, R. \& O'Connor, K.J. (2020), Does the U-shape pattern in life cycle satisfaction obscure reality? A Response to Blanchflower. Review of Behavioral Economics, 7: 201-206.

60). Ngoo, Y.T, Tan, E.C, and Tey, N.P. (2021), Determinants of life satisfaction in Asia: a quantile regression approach, Journal of Happiness Studies, 22, pp. 907-926.

61). Olivos, F, Olivos-Jara, P. \& Browne, M. (2021), Asymmetric social comparison and life satisfaction in social networks, Journal of Happiness Studies, 22, pp. 363-384.

62). Orben, A, R.E. Lucas, Fuhrmann, D. and Kievit, R.A. (2020), Trajectories of adolescent life satisfaction. PsyArXiv. August 20. 
63). Pancheva, M.G, Ryff, C.D. \& Lucchini, M. (2021), An integrated look at wellbeing: topological clustering of combinations and correlates of hedonia and eudaimonia, Journal of Happiness Studies, 22, 2275-2297.

64). Park, J, Joshanloo, M, and Scheifinger, H. (2020), Predictors of life satisfaction in Australia: A study drawing upon annual data from the Gallup World Poll. Australian Psychologist: 55(4), August, 375-388.

65). Piper, A. (2021), Temps dip deeper: temporary employment and the midlife nadir in human well-being, The Journal of the Economics of Aging, 19, June, 100,323.

66). Pontarollo, N, Orellana, M. \& Segovia, J. (2020), The determinants of subjective well-being in a developing country: the Ecuadorian case, Journal of Happiness Studies, 21, 3007-3035.

67). Posel, D, Bruce-Brand, J. (2020), Only a housewife?' subjective well-being and homemaking in South Africa, Journal of Happiness Studies.

68). Prior, L, K. Jones and Manley, D. (2020), Ageing and cohort trajectories in mental ill health; an exploration using multi-level models, Plos One, July 9th.

69). Ranjbar, S, Sperlich, S. (2020), A Note on Empirical Studies of Life-Satisfaction: Unhappy with Semiparametrics? Journal of Happiness Studies, 21, 2193-2212.

70). Ritschard, G. (2021). Measuring the nature of individual sequences, Sociological Methods \& Research in press.

71). Rohrer, J.M., M. Brümmer, J. Schupp and G. G. Wagner (2021), Worries across time and age in the German Socio-Economic Panel study, Journal of Economic Behavior \& Organization, 181, 332-343.

72). Sarracino, F, Piekałkiewicz, M. (2021), The role of income and social capital for Europeans' Well-being during the 2008 economic crisis, Journal of Happiness Studies, pp. 1583-1610.

73). Sato, K. (2021), Who is happier in Japan, a housewife or working wife? Journal of Happiness Studies, (2021), first online May 27.

74). Simona-Moussa, J. (2020), The subjective well-being of those vulnerable to poverty in Switzerland, Journal of Happiness Studies, 21, 1561-1580.

75). Salahodjaev, R. and N. Ibragimova (2020), Height and life satisfaction: evidence from Russia, Applied Research in Quality of Life, 15, 219-237.

76). Song, Y, Zhou, A. \& Zhang, M. (2020), Exploring the effect of subjective air pollution on happiness in China, Environmental Science \& Pollution Research, 27, 43,299-43,311.

77). Sørensen, J. (2021) The rural happiness paradox in developed countries, Social Science Research, in press.

78). Stone, A.A, J.E. Broderick, D. Wang and Schneider, S. (2020), Age patterns in subjective well-being are partially accounted for by psychological and social factors associated with aging, PlosOne.

79). Sun, B., J. Lin \& C. Yin (2021), How does commute duration affect subjective well-being? A case study of Chinese cities, Transportation, 48: 885-90.

80). Takao, T, N. Sumi, Y. Yamanaka, S. Fujimoto and T. Kamada, (2021), BioPsychosocial Medicine, 15:8.

81). Tsai, MC., (2021), Kin, friend and community social capital: effects on wellbeing and prospective life conditions in Japan, South Korea and Taiwan, Social Indicators Research, 154, pp. 489-510.

82). Ucal, M, Günay, S. (2021), Household happiness and fuel poverty: a cross-sectional analysis on Turkey. Applied Research in Quality Life. 
83). van Ours, J. (2021), What a drag it is getting old? Mental health and loneliness beyond age 50, Applied Economics.

84). Welsch, H, Bierman, P. \& Kühling, J. (2021), Immigration attitudes and subjective well-being: a matter of identity? Journal of Happiness Studies, 22, 1563-1581.

85). Woolf, S. (2020), COVID-19 as the leading cause of death in the United States, JAMA. Published online December 17, 2020.

86). Xu, W. H. Sun, B. Zhu, X. Yu, Y. Niu, C. Kou and W. Lia (2021), The prevalence of depressive symptoms and its determinants among adults in mainland China: Results from a national household survey, Journal of Affective Disorders, Volume 281, 15 February, pp. 220-227.

87). Želinský, T, O. Hudec, A. Mojsejová and S. Hricová (2021), The effects of population density on subjective well-being: A case-study of Slovakia, Socio-Economic Planning Sciences, Available online 21 March 2021, 101,061.

88). Zhang, Z. \& Wang, X. (2020), Ambition or jealousy? It depends on whom you are compared with, Journal of Happiness Studies, published online 25 May 2020.

\section{Papers Published as Chapters, Books or Working Papers Since 2019}

1). Badunenko, O., J.M. Cordero, Jose M. and S.C. Kumbhakar (2021), Are you slacking? Where do you and your country stand in the happiness pursuit? $16^{\text {th }}$ June, Munich Personal RePec Archive.

2). Becker, C. and S.T. Trautmann (2021), 1 Does happiness increase in old age? Longitudinal evidence from 20 European Countries, working paper University of Heidelberg. July.

3). Biermann, P. J. Bitzer and E. Gören (2021), The relationship between age and subjective well-being: estimating within and between effects simultaneously, working paper V-421-19 University of Oldenberg Department of Economics.

4). Biyase, M, B. Fisher and M. Pretorius (2020), Remittances and subjective wellbeing: A static and dynamic panel approach to single-item and multi-item measures of happiness, University of Johannesberg, EDWRG Working Paper Number 04-2020.

5). Blanchflower, D.G. and A.J. Bryson, Biden, Covid and Mental health in America, NBER Working paper \#29,040.

6). Blanchflower, DG \& Fair, D. (2021), Native Americans Native Americans' Experience of Chronic Distress in the USA, working paper.

7). Blanchflower, D.G. \& Graham, C. (2020a), The mid-life dip in well-being: economists (who find it), versus psychologists (who don't)! NBER Working Paper \#W26888.

8). Blanchflower, D.G. \& Graham, C. (2020b), Subjective well-being around the world: trends and predictors across the life span: a response, working paper.

9). Blanchflower, D.G. \& Graham, C. (2021), Happiness and ageing, in Handbook of the Economics of Ageing, edited by David Bloom, Alfonso Sousa-Poza and Uwe Sunde, Routledge, forthcoming.

10). Blanchflower, D.G. and Oswald, A.J. (2019), Is there a midlife psychological low? Two approaches (with and without controls), in six modern data sets on 1.3 million citizens? In M. Rojas (Ed.), The Economics of Happiness: How the Easterlin Paradox Transformed our Understanding of Well-being and Progress. New York: Springer.

11). Brown, S, Kontonikas, A, Montagnoli, A. et al. (+2 more authors), (2019), Life satisfaction and austerity: expectations and the macroeconomy. Working Paper. Sheffield Economic Research Paper Series, 2,019,011. 
12). Clark, A.E, (2019), Born to be mild? Cohort effects don't (fully), explain why wellbeing is U-shaped in Age. In: Rojas M (ed), The Economics of Happiness. How the Easterlin Paradox Transformed Our Understanding of Well-Being and Progress, 2019, Springer, pp 387-408.

13). Clark, A.E, Luis Diaz-Serrano (2021), The long-run effects of housing on wellbeing, Working paper 2021-32, Paris School of Economics.

14). de Pedraza, P, Guzi, M. and Tijdens, K. (2020), 'Life dissatisfaction and anxiety in COVID-19 pandemic,' GLO Discussion Paper, No. 544, May.

15). Ditlev-Simonsen, C.D. (2020), 'What is happiness to Norwegians-and how happy are they? Working paper 1/2020 Forum for Foundations, October 2020.

16). Gondek, D. Rebecca E. Lacey D.G. Blanchflower and Praveetha Patalay (2021), 'How is the distribution of psychological distress changing over time? Who is driving these changes? Analysis of the 1958 and 1970 British birth cohorts', MedRxiv.

17). Graham, C. (2019), Happiness for all. Unequal hopes and lives in pursuit of the American Dream, Princeton University Press.

18). Giuntella, O, S. McManus, R. Mujcic, A.J. Oswald (2019), Why is there so much midlife distress in affluent nations? Working Paper April.

19). Helliwell, J, Huang, H, Norton, M, and Wang, S. (2019), Happiness at different ages: the social context matters. In M. Rojas (Ed.), The Economics of Happiness: How the Easterlin Paradox Transformed our Understanding of Well-being and Progress. New York: Springer.

20). Kaiser, M. S. Otterbach and A. Sousa-Poza (2021), Using machine learning to uncover the relation between age and life satisfaction, working paper,

21). Kiseleva, L. (2020), 'Leading dominants of the subjective well-being: a case study of the Tyumen region, 6th International Conference on Social, economic, and academic leadership, Atlantis Press.

22). Li, A., T. Sato, and Y.Matsuda (2021), Spatial analysis of subjective well-being in Japan, Data Science and Service Research Discussion Paper No. 122, May, Tohoku University.

23). Macchia, L. and Plagnol, A.C. (2019), The subjective well-being political paradox: evidence from Latin America. In M. Rojas (Ed.), The Economics of Happiness: How the Easterlin Paradox Transformed our Understanding of Well-being and Progress. New York: Springer.

24). Måseide, H. (2021), Income and happiness. Does the relationship vary with age?, Master thesis, Umeå University, June.

25). Mirjana, G. (2019), 'Subjective well-being in a transition economy evidence from Macedonia,' University of Roehampton, PhD thesis.

26). Nguyen, CV (2021), Does the COVID-19 pandemic cause people to be unhappy? Evidence from a six-country survey,' GLO DP \#768, Essen.

27). Nie, P., Ma, W., \& Sousa-Poza, A. (2020). The relationship between smartphone use and subjective well-being in rural China. Electronic Commerce Research. https://doi. org/10.1007/s10660-020-09397-1

28). Nie, P., Q. Li \& A. Sousa-Poza (2021) Energy, poverty and subjective well-being in China: new evidence from China Family Studies, IZA Working Paper \#14,429.

29). Piper, A. (2021) What does dynamic panel analysis tell us about life satisfaction? working paper. July.

30). Toshkov, D. (2021), 'The relationship between age and happiness varies by income, Institute of Public Administration, Leiden University, the Netherlands. 
31). Vienne, V. (2019), Life satisfaction and air pollutipn in Latin America, working paper University of Manchester.

32). Wang, R. (2020), 'What makes residents of Canada happy? Determinants of life satisfaction in Canada,' University of Ottawa, MSc thesis.

33). Wayte, S. (2020), Addressing the midlife happiness 'dip': an evidence-informed mindfulness-based approach to support and promote women's well-being', Lesley University, thesis.

34). Yang, Y. (2020), 'The economics of psychological well-being: evidence from the United States using machine learning method, University of California Riverside.

35) Yodo, M. (2021), 'Does participation in community activities increase one's subjective well-being? Quantitative analysis considering causality and external effect in Japan,' Kier Discussion Paper \#1064, Kyoto Institute of Economic Research.

\section{Papers Published Pre 2013 in English in Peer Reviewed Journals}

1). Andrén, D. and P. Martinsson (2006), What contributes to life satisfaction in transitional Romania? Review of Development Economics, 10(1), pp. 59-70.

2). Appleton, S, \& Song, L. (2008), Life satisfaction in urban China: components and determinants, World Development, 36, 2325-2340.

3). Baird, B. M, Lucas, R. E, \& Donnellan, M. B. (2010), Life satisfaction across the life span: Findings from two nationally representative panel studies, Social Indicators Research, 99, 183-203.

4). Ball, R, \& Chernova, K. (2008), Absolute income, relative income and happiness, Social Indicators Research, 88(3), 497-529.

5). Bartram, D. (2013), Happiness and 'economic migration': A comparison of Eastern European migrants and stayers. Migration Studies, 1(2), 156-175.

6). Becchetti, L, Giachin Ricca, E. \& Pelloni, A. (2012), The relationship between social leisure and life satisfaction: causality and policy implications, Social Indicators Research, 108, 453-490.

7). Bell, D, \& Blanchflower, D. G. (2007), The Scots may be brave, but they are neither healthy nor happy, Scottish Journal of Political Economy, 54, 166-194.

8). Birdi, K. P. Warr and A.J. Oswald (1995), Age differences in three components of employee well-being, Applied Psychology, 44(4), pp. 345-373.

9). Bjørnskov, C, Dreher, A. \& Fischer, J.A.V. (2008), Cross-country determinants of life satisfaction: exploring different determinants across groups in society, Social Choice and Welfare, 30, 119-173.

10). Blanchflower, D. G. (2001), Unemployment, well-being and wage curves in Eastern and Central Europe, Journal of Japanese and International Economies, 15, 364-402.

11). Blanchflower, D, \& Oswald, A. (2004), Well-being over time in Britain and the United States', Journal of Public Economics, Volume 88, Issues 7-8, July, 1359-1386.

12). Blanchflower, D, \& Oswald, A. (2004), Money, sex and happiness, Scandinavian Journal of Economics, 106(3), 393-415.

13). Blanchflower, D, \& Oswald, A. (2008), Is well-being U-shaped over the life cycle? Social Science \& Medicine: 66(8), 1733-1741.

14). Blanchflower, D, \& Oswald, A. (2008), Hypertension and happiness across nations, Journal of Health Economics, 27(2), 218-233. 
15). Blanchflower, D, \& Oswald, A. (2009), The U-shape without controls: a response to Glenn, Social Science \& Medicine: 69, 486-488.

16). Blanchflower, D, \& Oswald, A. (2011), International happiness: a new view on the measure of performance, The Academy of Management Perspectives, February 2011, pp. $6-22$.

17). Brockmann, H. (2010), Why are middle-aged people so depressed? evidence from West Germany, Social Indicators Research, 97, 23-42.

18). Caporale, G. M, Georgellis, Y, Tsitsianis, N, \& Ping, Y. Y. (2009), Income and happiness across Europe: Do reference values matter? Journal of Economic Psychology, 30, $42-51$.

19). Carstensen, L. L, Turan, B, Scheibe, S, Ram, N, Ersner-Hershfield, H, SamanezLarkin, G. R, et al. (2011), Emotional experience improves with age: Evidence based on over 10 years of experience sampling. Psychology and Aging, 26(1), 21-33.

20). Choi, S.H. Are Koreans satisfied with life? SERI Quarterly, 1(1), January pp. $100-103$.

21). Clark, A. E. (2003), Unemployment as a social norm: Psychological evidence from panel data, Journal of Labor Economics, 21(2), 323-351.

22).Clark, A.E. (2005). Your money or your life: Changing job quality in OECD countries. British Journal of Industrial Relations, 43, 377-400.

23). Clark, A.E. and F. Etilé (2011), Happy house: Spousal weight and individual wellbeing, Journal of Health Economics, Volume 30, Issue 5, September, 1124-1136.

24). Clark, A, \& Oswald, A. (1994), Unhappiness and unemployment, The Economic Journal: 648-659.

25). Clark, A. E, Oswald, A, \& Warr, P. (1996), Is job satisfaction U-shaped in age? Journal of Occupational and Organizational Psychology, 69, 57-81.

26). Claudia, S. (2009), Direct evidence on income comparisons and their welfare effects, Journal of Economic Behavior and Organization, 72(2009), 408-424.

27). Cullis, J, Hudson, J. \& Jones, P. (2011), A different rationale for redistribution: pursuit of happiness in the European Union, Journal of Happiness Studies, 12, 323-341.

28). Cuñado, J, de Gracia, F.P. (2012), Does education affect happiness? Evidence for Spain, Social Indicators Research, 108, 185-196.

29). Davies, S, Hinks, T. (2010), Crime and happiness amongst heads of households in Malawi, Journal of Happiness Studies, 11, 457-476.

30). Di Tella, R, MacCulloch, R. J, \& Oswald, A. J. (2001), Preferences over inflation and unemployment: evidence from surveys of happiness, American Economic Review, 91, 335-341.

31). Di Tella, R, MacCulloch, R. J, \& Oswald, A. J. (2003), The macro- economics of happiness. Review of Economics and Statistics, 85, 809-827.

32). Easterlin, R. (2008) Lost in transition: Life satisfaction on the road to capitalism. Journal of Economic Behavior and Organization, 71:130-14.

33). Ferrante, F. (2009) Education, aspirations and life satisfaction,' Kyklos, 62(4), 542-562.

34). Ferrer-i-Carbonell, A. (2005), Income and well-being: an empirical analysis of the comparison income effect, Journal of Public Economics, 89, 997-1019.

35). Ferrer-i-Carbonell, A, \& Gowdy, J. M. (2007), Environmental awareness and happiness. Ecological Economics, 60(3), 509-516.

36). Ferrer-i-Carbonell, A, and P. Frijters (2004), How important is methodology for the estimates of the determinants of happiness? The Economic Journal, 114, 641. 
37). Frijters, P, Haisken-DeNew, J. P, \& Shields, M. A. (2004), Money does matter! Evidence from increasing real income and life satisfaction in East Germany following reunification. American Economic Review, 94, 730-740.

38). Frijters, P, Haisken-DeNew, J. P, \& Shields, M. A. (2005), The causal effect of income on health: evidence from German reunification, Journal of Health Economics, 24, 997-1017.

39). Fukuda, K. (2013), A happiness study using age-period-cohort framework, Journal of Happiness Studies, 14 (1), 135-53.

40). Georgellis, Y, Tsitsianis, N. \& Yin, Y.P. (2009), Personal values as mitigating factors in the link between income and life satisfaction: evidence from the European Social Survey, Social Indicators Research, 91, 329-344.

41). Gerdtham, U-G. and Johannesson, M. (2001), The relationship between happiness, health, and socio-economic factors: result based on Swedish microdata, Journal of SocioEconomics, 30(6), 553-557.

42). Gerlach, K, \& Stephan, G. (1996), A paper on unhappiness and unemployment in Germany. Economics Letters, 52, 325-330.

43). Gimenez-Nadal, J.I, Sevilla-Sanz, A. (2011), The time-crunch paradox, Social Indicators Research, 102, 181-196.

44). Graham, C. (2005). Insights on development from the economics of happiness. World Bank Research Observer, 20, 201-231.

45). Gwozdz, W. and A, Sousa-Poza (2010), Ageing, health and life satisfaction of the oldest old: an analysis of Germany, Social Indicators Research, 97, pp. 397-417.

46). Hayo, B, \& Seifert, W. (2003), Subjective economic well-being in Eastern Europe, Journal of Economic Psychology, 24, 329-348.

47). Helliwell, J. (2003). How's life? Combining individual and national variables to explain subjective well-being. Economic Modelling, 20, 331-360.

48). Helliwell, J.F.; Putnam, R.D. (2004), The social context of well-being. Philosophical transactions of the Royal Society of London. Series B, Biological Sciences, 359(1449), 1435-1446.

49). Helliwell, J.F. and H. Huang (2013), 'Comparing the happiness effects of real and on-line friends, PlosOne, September 320.

50). Helliwell, J.F. and S. Wang (2010), Trust and well-being, International Journal of Wellbeing, Vol. 1, No. 1, 42-78.

51). Hochwarter, W.A., G.R. Ferris, P. Perrewé, L. A. Witt, and C. Kiewitz (2006), A note on the nonlinearity of the age-job satisfaction relationship, Journal of Applied Social Psychology, 32(6), 1223-1237.

52). Hooghe, M, Vanhoutte, B. (2011), Subjective well-being and social capital in Belgian communities. the impact of community characteristics on subjective well-being indicators in Belgium, Social Indicators Research, 100, 17-36.

53). Humpert, S. (2010), A note on happiness in Eastern Europe. European Research Studies, Vol. XIII, No. 3: pp. 133-144.

54). Kuroki, M. (2011), Does social trust increase individual happiness in Japan? Japanese Economic Review, 62(4), 444-459.

55). Lacruz, M.E, Emeny, R.T, Baumert, J. et al. (2011), Prospective association between self-reported life satisfaction and mortality: Results from the MONICA/KORA Augsburg S3 survey cohort study. BMC Public Health, 11, 579.

56). Lang, I.A, Llewellyn, D.J, Hubbard, R.E, Langa, K.M, \& Melzer, D. (2011), Income and the midlife peak in common mental disorder prevalence, Psychological Medicine: 1365-1372. 
57). Lelkes, O. (2006), Knowing what is good for you: Empirical analysis of personal preferences and the "objective good. The Journal of Socio-Economics, 35(2), 285-307.

58). Long, A. (2005). Happily ever after? A study of job satisfaction in Australia.The Economic Record, 81, 303-321.

59). McAdams, K.K, Lucas, R.E, Donnellan, M.B. (2012), The role of domain satisfaction in explaining the paradoxical association between life satisfaction and age, Social Indicators Research: 295-303.

60). Morgan, J. and O. Robinson (2013), Intrinsic aspirations and personal meaning across adulthood: conceptual interrelations and age/sex differences', Developmental Psychology, 19(5), pp. 999-1010.

61). Movshuk, O. (2011), Why is life satisfaction U-shaped in age? Journal of Behavioral Economics and Finance, Vol 4, 133-138.

62). Mroczek, D. K, \& Christian, M. (1998), The effects of age on positive and negative affect: A developmental perspective on happiness, Journal of Personality and Social Psychology, 75(5), 1333-1349.

63). Mroczek, D.K., \& Kolarz, C.M. (1998). The effect of age on positive and negative affect: A developmental perspective on happiness. Journal of Personality and Social Psychology, 75, 1333-1349.

64). Mroczek, D.K., \& Spiro, A. (2005). Change in life satisfaction during adulthood: Findings from the Veterans Affairs Normative Aging study. Journal of Personality and Social Psychology, 88, 189-202.

65). Oshio, T, Kobayashi, M. (2011), Area-level income inequality and individual happiness: evidence from Japan, Journal of Happiness Studies, 12, 633-649.

66). Oswald, A. J. (1997), Happiness and economic performance. The Economic Journal, 107, 1815-1831.

67). Oswald, A. J, \& Powdthavee, N. (2005), Does happiness adapt? A longitudinal study of disability with implications for economists and judges, Journal of Public Economics, 92(5-6), June, pp. 1061-1077.

68). Oswald, A. J, \& Powdthavee, N. (2007), Obesity, unhappiness and the challenge of affluence: theory and evidence, The Economic Journal, 117(521), 441-454.

69). Oswald, A.J. (2010) Emotional propserity and the Stiglitz Commission, British Journal of Industrial Relations, 48(4), December, 651-669.

70). Oswald, A.J. and S. Wu (2011), Well-being across America, Review of Economics and Statistics, 2011, 93, 1118-1134.

71). Peiró, A. (2006), Happiness, satisfaction and socio-economic conditions: some international evidence, The Journal of Socio-Economics, 35(2), 348-365,

72). Pittau, M.G, Zelli, R. \& Gelman, A. (2010), Economic disparities and life satisfaction in European regions, Social Indicators Research, 96, 339-361.

73). Powdthavee, N. (2005), Unhappiness and crime: evidence from South Africa, Economica, 72, 531-547.

74). Propper, C, Jones, K, Bolster, A, Burgess, S, Johnston, R, \& Sarker, R. (2005), Local neighbourhood and mental health: evidence from the UK, Social Science \& Medicine, 61, 2065-2083.

75). Realo, A, \& Dobewall, H. (2011), Does life satisfaction change with age? A comparison of Estonia, Finland, Latvia, and Sweden, Journal of Research in Personality, 45(3), 297-308.

76). Safi, M. (2010), Immigrants' life satisfaction in Europe: Between assimilation and discrimination. European Sociological Review, 26(2), 159-176. 
77). Salinas-Jiménez, M.M, Artés, J. \& Salinas-Jiménez, J. (2011), Education as a positional good: a life satisfaction approach, Social Indicators Research, 103, 409-426.

78). Sanfey, P. and U. Teksoz (2007), Does transition make you happy? Economics of Transition, 15(4), 707-731.

79). Seifert, W, (2003), Subjective economic well-being in Eastern Europe, Journal of Economic Psychology, 24 (3), 329-34.

80). Senik, C. (2004), When information dominates comparison-learning from Russian subjective panel data, Journal of Public Economics, 88, 2099-2123.

81). Shields, M. A, \& Wheatley Price, S. (2005), Exploring the economic and social determinants of psychological well-being and perceived social support in England, Journal of the Royal Statistical Society (Series A), 168, 513-537.

82). Smyth, R, Nielsen, I. \& Zhai, Q. (2010) Personal well-being in urban China, Social Indicators Research, 95, 231.

83). Sohn, K. (2013), Sources of happiness in Indonesia, The Singapore Economic Review, Vol. 58, No. 02, 1,350,014.

84). Sook-Hee, C. (2008), Are Koreans satisfied with life? SERI Quarterly; Vol. 1(1), $100-103$.

85). Stone, A.A. J.E. Schwartz, J. E. Broderick, and A. Deaton (2010), 'A snapshot of the age distribution of psychological well-being in the United States,'PNAS, June 1, 107 (22): 9985-9990.

86). Subramanian, S.V, Kim, D, Kawachi, I. (2005), Covariation in the socioeconomic determinants of self-rated health and happiness: a multivariate multilevel analysis of individuals and communities in the USA. Journal of Epidemiology and Community Health, 59(8), 664-669.

87). Sun, F, Xiao, J.J. (2012) Perceived social policy fairness and subjective wellbeing: evidence from China, Social Indicators Research, 107, 171-186.

88). Theodossiou, I. (1998), The effects of low-pay and unemployment on psychological well-being: a logistic regression approach, Journal of Health Economics, 17, 85-104.

89). Tsou, M, \& Liu, J. (2001), Happiness and domain satisfaction in Taiwan, Journal of Happiness Studies, 2, 269-288.

90). Uppal, S. (2006), Impact of the timing and severity of disability on the subjective well-being of individuals with disabilities, Social Science \& Medicine, 63, 525-539.

91). Van Landeghem, B. (2009). The course of subjective well-being over the life cycle: Schmollers Jahrbuch, 129(2), 261-267.

92). Van Landeghem, B. (2012), A test for convexity of human well-being over the lifecycle: longitudinal evidence from a 20-year panel, Journal of Economic Behavior and Organization: 571-585.

93). Van Landeghem, B. and J. Schmollers (2009), The course of subjective wellbeing over the life cycle, Journal of Applied Social Science Studies, 129(2), (Apr 2009): 261-267.

94). Van Laningham, J. D. R. Johnson and P. Amato (2001), Marital happiness, marital duration, and the U-shaped curve: evidence from a five-wave panel study, Social Forces, Volume 79, Issue 4, June, pp. 1313-1341.

95). Wang, P, VanderWeele, T.J. (2011) Empirical research on factors related to the subjective well-being of Chinese urban residents, Social Indicators Research, 101, 447-459.

96). Winkelmann, L., \& Winkelmann, R. (1998). Why are the unemployed so unhappy? Evidence from panel data, Economica, 65, 1-15.

97). Yang, Y. (2008), Social inequalities in happiness in the United States, 1972 to 2004: An age-period-cohort analysis, American Sociological Review, 73(2), 204-226. 
Acknowledgements We thank Dan Gilbert of Harvard University for his helpful comments and advice on this project.

Funding Not applicable.

Data Availability The Annual Population Survey is available at the UK Data Archive https://beta.ukdat aservice.ac.uk/datacatalogue/studies/study?id=8789\#!/resources. Eurobarometer Surveys are available from https://zacat.gesis.org. Household Pulse Surveys are available from the US Census Bureau. Gallup World Poll data available by subscription.

\section{Declarations}

Conflict of interest The authors declare that they have no conflicts of interest.

\section{References}

Argyle, M. (1999). Causes and correlates of happiness. In D. Kahneman, E. Diener, \& N. Schwarz (Eds.), Wellbeing: The Foundations of Hedonic Psychology (pp. 353-373). Russell Sage.

Argyle, M. (2001). The Psychology of Happiness (2nd ed.). Routledge.

Bittmann, F. (2021). Beyond the U-shape: Mapping the functional form between age and life satisfaction for 81 countries utilizing a cluster procedure. Journal of Happiness Studies, 22, 2343-2359. https://doi. org/10.1007/s10902-020-00316-7

Blanchflower, D.G. and, A.J. Oswald (2019). Do modern humans suffer a psychological low in midlife? Two approaches (with and without controls) in seven data sets. In The Economics of Happiness. How the Easterlin Paradox Transformed Our Understanding of Well-Being and Progress, edited by Mariano Rojas, Springer.

Blanchflower, D.G. and C. Graham (2020). The mid-life dip in well-being: economists (who find it) versus psychologists (who don't)! NBER Working Paper \#26888.

Blanchflower, D.G. and D. Feir (2021). Native Americans and despair in the United States. Working paper.

Blanchflower, D.G. and A. Bryson (2021). Biden, Covid and mental health in America, NBER Working Paper \#29040.

Blanchflower, D.G. and C. Graham (2021b). Happiness and ageing, Forthcoming in Handbook of the Economics of Ageing, edited by David Bloom, Alfonso Sousa-Poza and Uwe Sunde, Routledge, was NBER Working Paper \#28143.

Blanchflower, D.G. (2021). A Response to 'Another attempt to move beyond the cross-sectional U shape of happiness: a reply’ by Galambos, Krahn, Johnson and Lachman (2021), working paper https://cpb-use1.wpmucdn.com/sites.dartmouth.edu/dist/5/2216/files/2021/05/Galambos-reply-review.pdf

Blanchflower, D.G. and C. Graham (2021a). The U-shape of happiness: A response. Perspectives in Psychological Science, forthcoming.

Blanchflower, D. G. (2020a). Experienced life cycle satisfaction in Europe: A comment. Review of Behavioral Economics, 7(2), 201-206. https://doi.org/10.1561/105.00000120

Blanchflower, D. G. (2020b). Is happiness U-shaped everywhere? Age and subjective well-being in 145 countries. Journal of Population Economics, 34, 575-624.

Blanchflower, D. G. (2020c). Unhappiness and age. Journal of Economic Behavior and Organization, 176, 461-488. https://doi.org/10.1016/j.jebo.2020.04.022

Blanchflower, D. G., \& Clark, A. E. (2019). Children, unhappiness and family finances: Evidence from one million Europeans. Journal of Population Economics, 34, 625-653. https://doi.org/10.1007/ s00148-020-00798-y

Blanchflower, D. G., \& Oswald, A. J. (2004a). Money, sex and happiness: An empirical study. Scandinavian Journal of Economics, 106(3), 393-415. https://doi.org/10.1111/j.0347-0520.2004.00369.x

Blanchflower, D. G., \& Oswald, A. J. (2004b). Well-being over time in Britain and the USA. Journal of Public Economics, 88(7-8), 1359-1386. https://doi.org/10.1016/S0047-2727(02)00168-8

Blanchflower, D. G., \& Oswald, A. J. (2008). Is well-being U-shaped over the life cycle? Social Science and Medicine, 66, 1733-1749. https://doi.org/10.1016/j.socscimed.2008.01.030

Blanchflower, D. G., \& Oswald, A. J. (2009). The U-shape without controls: A response to Glenn. Social Science and Medicine, 69, 486-488. https://doi.org/10.1016/j.socscimed.2009.05.022 
Blanchflower, D. G., \& Oswald, A. J. (2016). Anti-depressants and age: A new form of evidence for U-shaped well-being through life. Journal of Economic Behavior and Organization, 127, 46-58. https://doi.org/10.1016/j.jebo.2016.04.010

Blanchflower, D. G., \& Oswald, A. J. (2020). Trends of extreme distress in the USA, 1993-2019. American Journal of Public Health, 110, 1538-1544. https://doi.org/10.2105/AJPH.2020.305811

Cantril, H. (1965). The Pattern of Human Concerns. Rutgers University Press.

Carstensen, L. L., Turan, B., Scheibe, S., Ram, R., Ersnser-Hershfield, H. G. R., Brooks, S. L., \& Nesselroade, J. R. (2011). Emotional experience improves with age: Evidence based on over 10 years of experience sampling. Psychology and Aging, 26, 21-33. https://doi.org/10.1037/a0021285

Case, A., \& Deaton, A. (2015). Rising morbidity and mortality in midlife among white non- Hispanic Americans in the 21st century. Proceedings of the National Academy of Sciences, 112(49), 1507815083. https://doi.org/10.1073/pnas.1518393112

Case, A., \& Deaton, A. (2020). Deaths of Despair and The Future of Capitalism. Princeton University Press.

Cheng, T. C., Powdthavee, N., \& Oswald, A. J. (2017). Longitudinal evidence for a midlife nadir: Result from four data sets. Economic Journal, 127, 126-142. https://doi.org/10.1111/ecoj.12256

Clark, A.E. (2019). Born to be mild? cohort effects don't (fully) explain why well-being is U- shaped in Age,' in The Economics of Happiness. How the Easterlin Paradox Transformed Our Understanding of Well-Being and Progress, edited by Mariano Rojas, Springer, (387-408).

Daly, M. C., Oswald, A. J., Wilson, D. J., \& Wu, S. (2011). Dark contrasts: The paradox of high rates of suicide in happy places. Journal of Economic Behavior \& Organization, 80(3), 435-442. https://doi. org/10.1016/j.jebo.2011.04.007

Deaton, A. (2008). Income, health, and well-being around the world: evidence from the Gallup World Poll. Journal of Economic Perspectives, 22(2), 53-72. https://doi.org/10.1257/jep.22.2.53

Deaton, A. (2018). What do self-reports of wellbeing say about life-cycle theory and policy? Journal of Public Economics, 162, 18-25. https://doi.org/10.1016/j.jpubeco.2018.02.014

Diener, E., \& Suh, E. M. (1998). Subjective well-being and age: An international analysis. Annual Review of Gerontology and Geriatrics, Chapter, 11(17), 304-324.

Diener, E., Suh, E. M., Lucas, R. E., \& Smith, H. L. (1999). Subjective well-being: three decades of progress. Psychological Bulletin. https://doi.org/10.1037/0033-2909.125.2.276

Easterlin, R. (2011). Happiness, Growth, and the Life Cycle. Oxford University Press.

Freund, A. M., \& Baltes, P. B. (1998). Selection, optimization and compensation as strategies of life management: correlations with subjective indicators of successful aging. Psychology and Aging, 13, 531543. https://doi.org/10.1037/0882-7974.13.4.531

Galambos, N.L. H.J. Krahn, M.D. Johnson, and M.E. Lachman (2021b). Another attempt to move beyond the U-shape: a reply. Perspectives in Psychological Science, forthcoming

Galambos, N.L. H.J. Krahn, M.D. Johnson, and M.E. Lachman (2021a). Another attempt to move beyond the U-shape. Perspectives in Psychological Science, forthcoming

Glenn, N. (2009). Is the apparent U-shape of well-being over the life course a result of inappropriate use of control variables? A commentary on Blanchflower and Oswald (66:8, 2008, 1733-1749). Social Science and Medicine, 69(4), 481-485. https://doi.org/10.1016/j.socscimed.2009.05.038

Gondek, D., Bann, D., Patalay, P., Goodman, A., McElroy, E., Richards, M., \& Ploubidis, G. B. (2020). Psychological distress from early adulthood to early old age: Evidence from the 1946, 1958 and 1970 British birth cohorts. Psychological Medicine. https://doi.org/10.1017/S003329172000327X

Graham, C. and S. Pettinato (2002). Happiness and Hardship: Opportunity and Insecurity in New Market Economies, The Brookings Institution Press.

Graham, C., (2017). Happiness for All? Unequal Lives and Hopes in Pursuit of the American Dream, Princeton University Press.

Graham, C. and S. Pinto (2018). Unequal hopes and lives in the U.S.A.: optimism, race, place, and premature mortality. Journal of Population Economics, Doi: https://doi.org/10.1007/ s00148-018-0687-y

Graham, C., K. Laffan and S. Pinto (2018). Well-being in metrics and policy. Science, 362(6412), 19 October. Doi: https://doi.org/10.1126/science.aau5234

Graham, C. (2010). Happiness around the World: The Paradox of Happy Peasants and Miserable Millionaires. Oxford University Press.

Graham, C., \& Pinto, S. (2021). The geography of desperation in America: Labor force participation, mobility, place, and well-being. Social Science and Medicine. https://doi.org/10.1016/j.socscimed. 2020.113542

Graham, C., \& Ruiz-Pozuelo, J. (2017). Happiness, stress, and age: How the U curve varies across people and places. Journal of Population Economics, 30, 225-264. https://doi.org/10.1007/ s00148-016-0611-2 
Gross, J., et al. (1997). Emotion and aging: experience, expression and control. Psychology and Aging, 12(4), 590-599. https://doi.org/10.1037/0882-7974.12.4.590

Helson, R., \& Lohnen, E. C. (1998). Affective coloring of personality from young adulthood to midlife. Personality and Social Psychology Bulletin, 24(3), 241-252. https://doi.org/10.1177/0146167298 243002

Hudomiet, P, M.D. Hurd, and S. Rohwedder (2021). The age profile of life-satisfaction after age 65 in the US, Journal of Economic Behavior and Organization, forthcoming.

Ingelhart, R. (1990). Culture Shift in Advanced Industrial Society. Princeton University Press.

Jebb, A. T., Morrison, M., Tay, L., \& Diener, E. (2020). Subjective well-being around the world: trends and predictors across the life span. Psychological Science. https://doi.org/10.1177/0956797619 898826

Lachman, M.E. (2015), Mind the gap in the middle: a call to study midlife. Research in Human Development, 12, 327-334.

Morgan, R., \& O'Connor, K. J. (2017). Experienced life cycle satisfaction in Europe. Review of Behavioral Economics, 4, 371-396. https://doi.org/10.1561/105.00000070

Morgan, R., \& O'Connor, K. J. (2020). Does the U-shape pattern in life cycle satisfaction obscure reality? A response to Blanchflower. Review of Behavioral Economics, 7(2), 201-206. https://doi.org/ $10.1561 / 105.00000122$

Myers, D. G. (1992). The Pursuit of Happiness. Avon Books.

Myers, D. G. (2000). The funds, friends, and faith of happy people. American Psychologist, 55(1), 56-67. https://doi.org/10.1037/0003-066X.55.1.56

Okma, P. and R. Veenhoven (1996). Is a longer life a better life? Happiness of the very old in 8 EU countries. Working paper.

Palmore, E., \& Luikart, C. (1972). Health and social factors related to life satisfaction. Journal of Health and Social Behavior, 13(1), 68-78.

Prenda, K., \& Lachman, M. E. (2001). Planning for the future: A life management strategy for increasing control and life satisfaction in adulthood. Psychology and Aging, 16(2), 206-216. https://doi.org/ 10.1037/0882-7974.16.2.206

Prior, L., K. Jones and D. Manley (2020). Ageing and cohort trajectories in mental ill-health: An exploration using multilevel models. PlosOne, July 9 https://doi.org/10.1371/journal.pone.0235594

Rauch, J. (2018). The Happiness Curve: Why Life Gets Better after 50. St. Martin's Press.

Steptoe, A., Deaton, A., \& Stone, A. A. (2015). Subjective wellbeing, health, and ageing. The Lancet, 385, 640-648. https://doi.org/10.1016/S0140-6736(13)61489-0

Stone, A.A., J.E. Schwartz, J. E. Broderick, and A. Deaton (2010). A snapshot of the age distribution of psychological well-being in the United States. Proceedings of the National Academy of Sciences of the United States, June, 107(22), 9985-9990.

Lara B. Aknin, Jan-Emmanuel De Neve, Elizabeth W. Dunn, Daisy E. Fancourt, Elkhonon Goldberg, John Helliwell, Sarah P. Jones, Elie Karam, Richard Layard, Sonja Lyubomirsky, Andrew Rzepa, Shekhar Saxena, Emily M. Thornton, Tyler J. Vander Weele, Ashley V. Whillans, Jamil Zaki, Ozge Karadag Caman, Yanis Ben Amor (2020). A Review and Response to the Early Mental Health and Neurological Consequences of the COVID-19 Pandemic. The Lancet's COVID-19 Commission Mental Health Task Force, PsyArXiv Preprints. https://psyarxiv.com/zw93g/

Ulloa, B. F. L., Moller, V., \& Sousa-Poza, A. (2013). How does subjective well-being evolve with age? A literature review. Journal of Population Ageing, 6(3), 227-246.

Wareham, C.S. (2021). Between hoping to die and longing to live longer. History and Philosophy of the Life Sciences, 43, paper \#40. https://doi.org/10.1007/s40656-021-00385-8

Weiss, A., J.E. King, M. Inoue-Murayama M, T. Matsuzawa and A.J. Oswald A.J. (2012). Evidence for a midlife crisis in great apes consistent with the U-shape in human well-being. Proceedings of the National Academy of Sciences, December 4, 109 (49), 19949-19952. https://https://doi.org/10.1073/ pnas. 1212592109

Xing, Z., \& Huang, L. (2014). The relationship between age and subjective well-being: Evidence from five capital cities in Mainland China. Social Indicators Research, 117, 743-756. https://doi.org/10.1007/ s11205-013-0396-6

Publisher's Note Springer Nature remains neutral with regard to jurisdictional claims in published maps and institutional affiliations. 